2013

STUDY OF SPARK IGNITION ENGINE COMBUSTION MODEL FOR THE ANALYSIS OF CYCLIC VARIATION AND COMBUSTION STABILITY AT LEAN OPERATING CONDITIONS

$\mathrm{Hao} \mathrm{Wu}$

Michigan Technological University

Follow this and additional works at: https://digitalcommons.mtu.edu/etds

Copyright 2013 Hao Wu

Recommended Citation

Wu, Hao, "STUDY OF SPARK IGNITION ENGINE COMBUSTION MODEL FOR THE ANALYSIS OF CYCLIC VARIATION AND COMBUSTION STABILITY AT LEAN OPERATING CONDITIONS", Master's report, Michigan Technological University, 2013.

https://doi.org/10.37099/mtu.dc.etds/662 


\title{
STUDY OF SPARK IGNITION ENGINE COMBUSTION MODEL FOR THE ANALYSIS OF CYCLIC VARIATION AND COMBUSTION STABILITY AT LEAN OPERATING CONDITIONS
}

\author{
By \\ $\mathrm{Hao} \mathrm{Wu}$ \\ A REPORT \\ Submitted in partial fulfillment of the requirements for the degree of \\ MASTER OF SCIENCE \\ In Mechanical Engineering \\ MICHIGAN TECHNOLOGICAL UNIVERSITY \\ 2013 \\ (C) $2013 \mathrm{Hao} \mathrm{Wu}$
}


This report has been approved in partial fulfillment of the requirements for the Degree of MASTER OF SCIENCE in Mechanical Engineering.

Department of Mechanical Engineering-Engineering Mechanics

Report Advisor: Dr. Bo Chen

Committee Member: Dr. Jeffrey D. Naber

Committee Member: $\quad$ Dr. Chaoli Wang

Department Chair: Dr. William W. Predebon 


\section{CONTENTS}

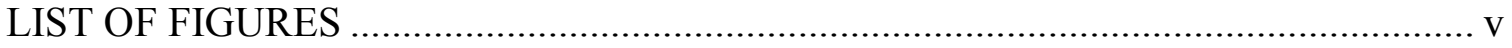

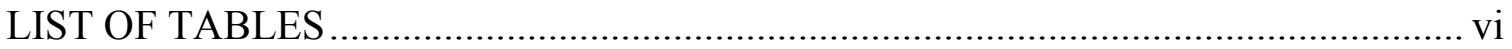

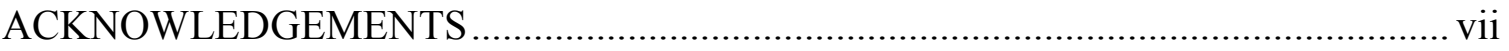



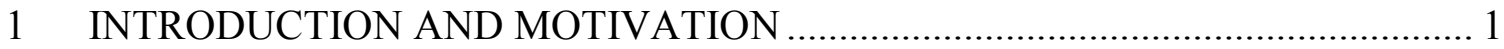

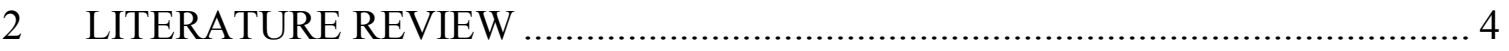

2.1 LEAN COMBUSTION ANALYSIS ......................................................... 4

2.2 FUNDAMENTAL COMBUSTION MODEL ................................................ 5

2.3 TWO-ZONE HEAT RELEASE MODEL ....................................................... 7

2.4 CYCLIC VARIATION IN ENGINE COMBUSTION ................................... 8

3 MEAN-VALUE FUNDAMENTAL COMBUSTION MODEL FOR SPARK-

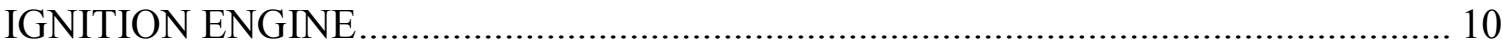

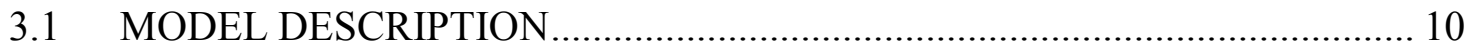

3.1.1 TURBULENT ENTRAIMENT AND EDDY-BURN MODEL ................ 10

3.1.2 COMBUSTION VARIABLES ........................................................... 12

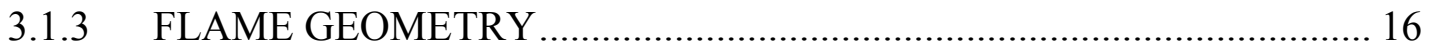

3.1.4 TWO-ZONE THERMODYNAMIC MODEL ........................................... 19

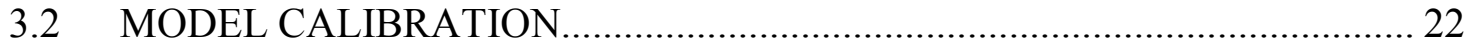

3.2.1 MODELING \& CALIBRATION ENVIRONMENT ................................. 22

3.2.2 ENGINE AND OPERATING PARAMETERS USED IN SIMULATION 23

3.2.3 CALIBRATION OF MODEL PARAMETERS....................................... 24

3.3 MODEL VALIDATION AND EXPERIMENTAL TEST RESULTS.............. 30

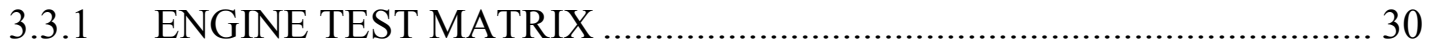

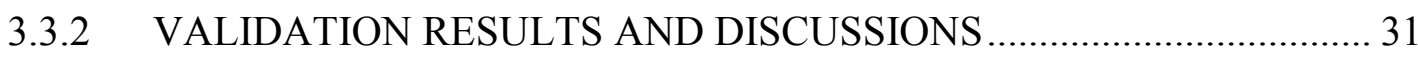

4 STUDY CYCLIC VARIATION USING DEVELOPED COMBUSTION MODEL 38

4.1 CYCLIC VARIATION IN ENGINE COMBUSTION 38 


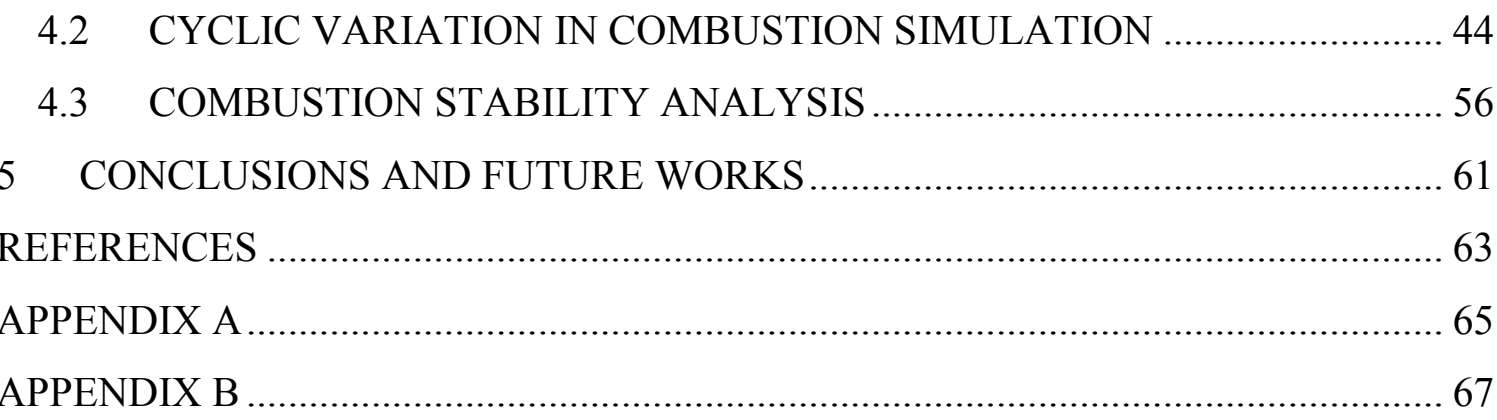




\section{LIST OF FIGURES}

Figure 3.1 :

Figure 3.2 :

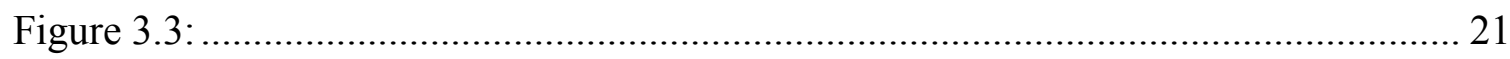

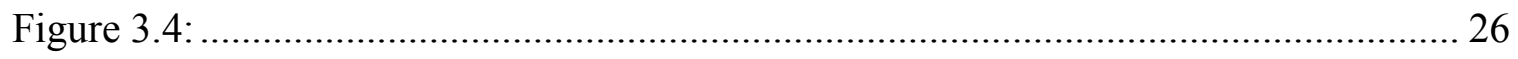

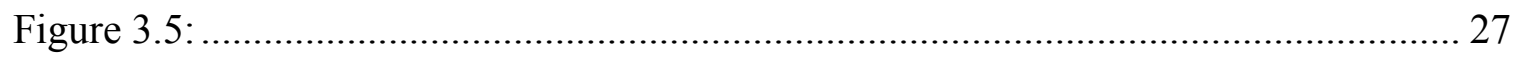

Figure 3.6:

Figure 3.7:



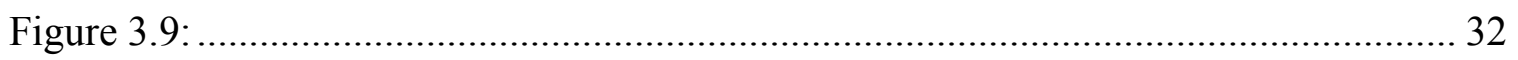

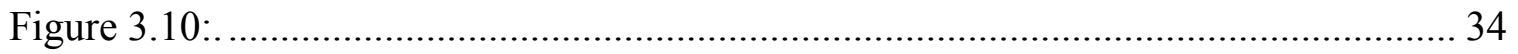

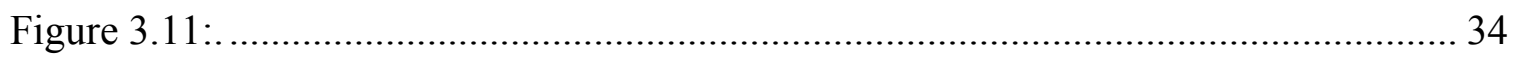

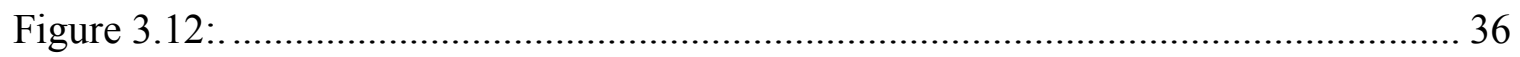

Figure 3.13:

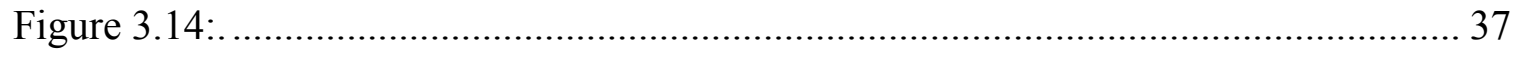

Figure 4.1 :

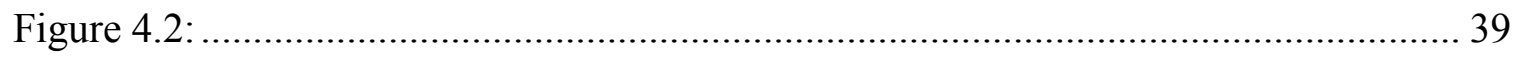

Figure 4.3:

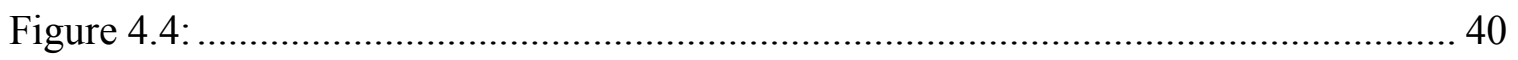

Figure 4.5 :

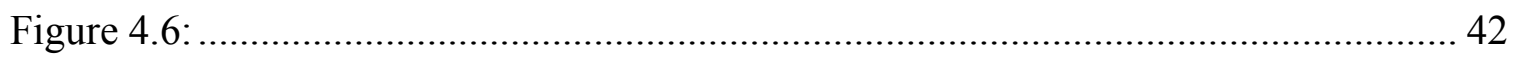

Figure 4.7:

Figure 4.8:

Figure 4.9:

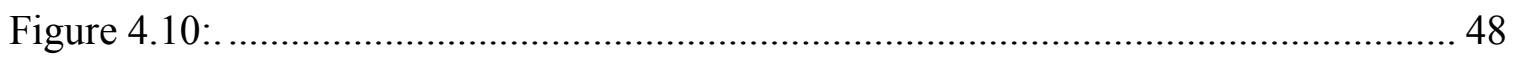

Figure 4.11:

Figure 4.12:



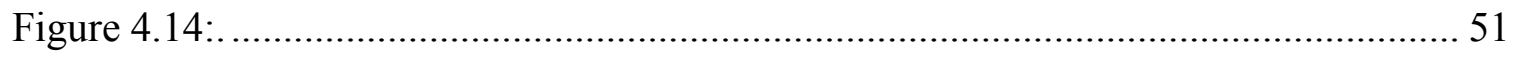

Figure 4.15:



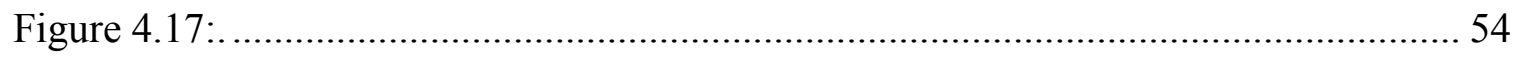

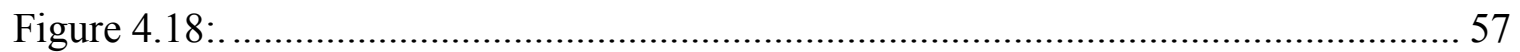

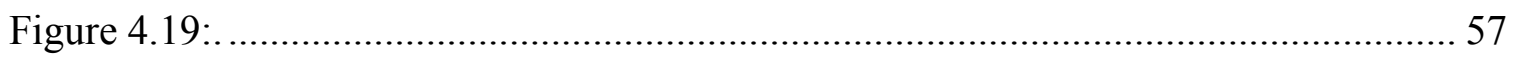

Figure 4.20 :

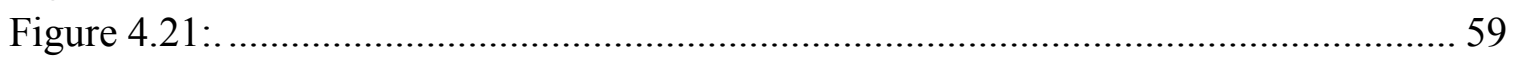

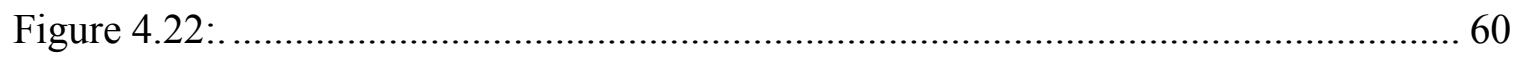

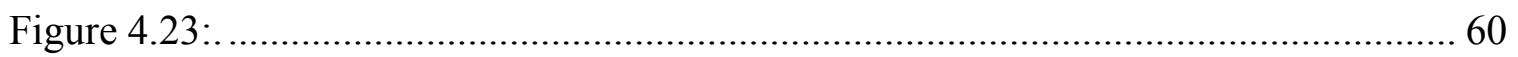




\section{LIST OF TABLES}

Table 3.1: Engine information and operating conditions used for simulation.................. 24

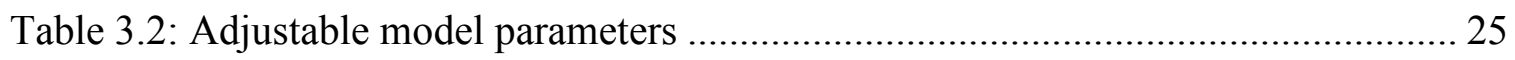

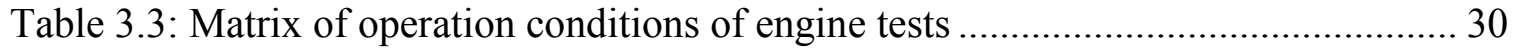



Table 3.5: Comparisons of CA10, CA50 and CA90 between experimental data and



Table 4.1: Amounts of introduced variation sources of engine inputs and parameters .... 45

Table 4.2: Other variation sources and their amount introduced in combustion model... 47

Table 4.3: Variances of introduced variation sources in simulations of under different

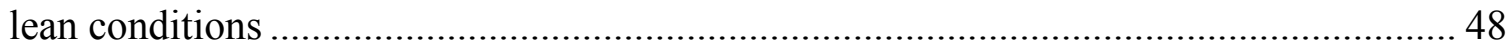

Table 4.4: COV of IMEP of simulation and experimental results............................... 55 


\section{ACKNOWLEDGEMENTS}

Firstly I will thank my advisor Dr. Bo Chen for her advices of this report and opportunity she provided for me to work in IC engine area. I would also thank Dr. Naber and Dr. Wang for joining in the committee and providing me valuable opinion.

Thanks to all the lab mates in Intelligent Mechantronics and Embedded Systems Lab with whom I have shared unforgettable time of study, work and life together. Thank all the friends in Michigan Technological University for their help and encouragement in life and work during these two years.

I appreciate the graduate research assistants who work in the Advance IC Engines Lab. Their precious engine experimental data give me irreplaceable help to complete this report.

The most people I need to thank are my parents who gave me their best and firm support and encouragement to my study abroad. I will always remember their devotion to me and use the effort of hard working to bring them hope in return. 


\begin{abstract}
A fundamental combustion model for spark-ignition engine is studied in this report. The model is implemented in SIMULINK to simulate engine outputs (mass fraction burn and in-cylinder pressure) under various engine operation conditions. The combustion model includes a turbulent propagation and eddy burning processes based on literature [1]. The turbulence propagation and eddy burning processes are simulated by zero-dimensional method and the flame is assumed as sphere. To predict pressure, temperature and other in-cylinder variables, a two-zone thermodynamic model is used. The predicted results of this model match well with the engine test data under various engine speeds, loads, spark ignition timings and air fuel mass ratios. The developed model is used to study cyclic variation and combustion stability at lean (or diluted) combustion conditions. Several variation sources are introduced into the combustion model to simulate engine performance observed in experimental data. The relations between combustion stability and the introduced variation amount are analyzed at various lean combustion levels.
\end{abstract}




\section{INTRODUCTION AND MOTIVATION}

For more than one century internal combustion (IC) engine has been a major power source for automobile. However, the limited fossil fuel resource available in the world and the restricted emission standards make IC engine development more challenging to meet fuel and emission requirements. In the observation of experimental results, sparkignition engine has better fuel economy and NOx emission in lean or diluted combustion conditions since in-cylinder temperature during combustion is reduced while maintaining same level of output power. However, lean condition will cause combustion stability to deteriorate. Such deterioration, once increasing to a certain level, some engine metrics become worse and then fuel economy follows. Consequently the engine efficiency could be improved by operating in lean condition but the concern about combustion stability limits its effect.

The information of mass fraction burned (MFB) is important in the analysis of engine combustion. Such information could be obtained with the in-cylinder pressure data which could be real-time captured through in-cylinder pressure transducers and rapid data acquisition/analysis systems. The indicated mean effective pressure (IMEP) is an indicator of combustion output power. This is calculated by integrating pressure with chamber instant volume. And from the MFB versus crank angle curves the information of heat release and burn duration could be known. Those are metrics used for analysis of combustion. From test results of consecutive combustion cycles the cyclic variation could be found in the pressure data, and also will be in the MFB ones. The statistic indicator that is coefficient of variance (COV) of IMEP is usually used to represent the stability of combustion. Such indicator could be rapidly calculated by analyzer with instantaneous pressure data.

To study lean combustion and its stability, a fundamental combustion model including physical processes of combustion and heat release should be very helpful. With the availability of different kinds of optical combustion engines or vessels and rapid imaging or signal measurement facilities, many researchers ([2-5]) have worked in observing the process of combustion under different conditions and deriving the expression of 
combustion variables. Base on the accessibility of such combustion variables and the visible processes of combustion flame propagation, researchers $([1,5-8])$ have built combustion model in spark-ignition (SI) engine including physical relations like turbulent flame propagation and eddy burned processes to predict the fuel mass burned rate.

For the modeling of mass fraction burned curves, empirical functions like Wiebe function are widely used with several parameters to be adjusted. Such methods could be convenient to use to predict heat release curve for individual cycle. However, fundamental combustion model has the advantage to apply under wide range of operation conditions due to physical-based relations are included in the model. The heat release information is the result of many complicated processes. Even if there is empirical expression to model MFB information, the parameters of the expression probably have no apparent trends or relations with the change of operation conditions. The combustion models introduced in this report are developed to express flame structure and burning process with the results of experimental observation. The model accuracy depends on the chosen of parameters in both the relations of the model and the combustion environmental conditions. The predicted results through combustion model can match the engine tests ones perfectly with well calibrated parameters in one case. Under different operation conditions that are considered in the model, it should still have the ability to predict approximate results for each.

Besides the mean value trends changes along with the changing of operation condition, the cycle-to-cycle variation in measured in-cylinder pressure histories also changes especially under different lean or diluted levels. The variations also exist in the MFB curves calculated from the pressure signals. Study the features of cyclic variations in the combustion processes could be helpful and somehow necessary to understand lean combustion and the lean limits come from instability. Such variations may be resulted by not only the fluctuations of inputs or environment but also the random natures of flame propagation and combustion. One advantage of fundamental combustion model is that the random natures could be considered and simulated in the model to predicting outputs with cyclic variations. That provides the availability to introduce variation sources with 
reasonable variance amount in purpose of obtaining in-cylinder pressure results with same cyclic variance level as that of experimental data.

A fundamental combustion model should have ability to predict MFB, in-cylinder pressure values and other intermediate variables. Some of them may not be easily observed from experiments under a wide range of operation condition. The qualified model could help to provide physical explanations of lean combustion phenomena, to help researchers understand how lean condition and combustion stability affect the fuel economy. If the combustion model is good enough to precisely simulate engine performance while changing engine inputs, it could also help to test engine strategy to see if it fulfills the control requirements.

In this report, a historical developed fundamental combustion model is studied and implemented. The performance of the developed combustion model is compared with several engine test data set under different operation conditions. The presented model includes turbulent propagation and eddy burned model introduced in [9] for mass burned prediction. And a two-zone thermodynamic model in [10] is used for in-cylinder pressure, mass density and temperature prediction. By introducing the randomness in combustion variables and engine inputs, model is able to simulate the cyclic variations of in-cylinder pressure data of consecutive cycles. The features of combustion instability of lean combustion are studied with the simulation results from this model. 


\section{LITERATURE REVIEW}

\subsection{LEAN COMBUSTION ANALYSIS}

Ayala et al. [11] analyze the features of lean combustion for SI engine under wide range of operation conditions. A general phenomenon is that both engine efficiency and the COV of IMEP increase as lambda value (lean level) increases. The COV of IMEP increases slowly at the beginning, and after a certain lean point is reached, it raises sharply. At the same time, the engine efficiency decreases after the lambda point where combustion stability becomes to deteriorate. In paper [11], combustion metrics such as burned durations are analyzed based on engine experimental results over wide range of operation conditions. The authors found that the peak engine efficiency corresponding to about $30 \mathrm{deg}$ of $10 \sim 90 \%$ burn duration in all test. The tests also show that $2 \% \mathrm{COV}$ of IMEP, which is often used as the stability threshold, is corresponding to about $40 \mathrm{deg}$ of $0 \sim 10 \%$ burn duration. The effect of cyclic combustion variability is also studied since it is closely related to the efficiency change with lambda. Base on the analysis of burn duration and IMEP of lean combustion with fixed average load, following features are found. (1) The distribution of $10 \sim 90 \%$ burn duration is close to a normal distribution when the lean level is low and the cyclic variation increases as lean level increases while the distribution becomes asymmetric. (2) The distributions of $0 \sim 10 \%$ burn duration keep normal distribution even though the combustion becomes more unstable. However the average value of $0 \sim 10 \%$ changes significantly as lean level increases. (3) The skew like distribution of 10 90\% burn duration also appears in the distribution of IMEP. There are small amount of cycles with extremely small IMEP values which correspond to large $10 \sim 90 \%$ burn duration. These cycles are bad combustion cycles (partial burned or misfire) which reduce the efficiency of engine.

Ayala et al. [1] continues to study the feature of lean combustion with engine test data and the fundamental combustion model they implemented. For the case of three individual tests if two of them have same bias in opposite directions at the beginning of the combustion, their deviations to the third one become large and unequal at the end of combustion. This is why $10 \sim 90 \%$ burn duration varies significantly at very lean 
condition. They also conclude that the cycle-to-cycle variability of combustion has close relation with the early growth of flame. This is also found from the distribution of $0 \sim 10 \%$ burn durations since their average values under different lean conditions change significantly. The major cause of the slow mass burning at the early stage of combustion is found due to the long eddy burning time under lean combustion with the help of developed combustion model.

\subsection{FUNDAMENTAL COMBUSTION MODEL}

The combustion model implemented in this report includes turbulent flame propagation and eddy burning process. Heywood introduces the turbulence flow with three characteristic scale lengths in IC engine combustion chamber in his book [12]. The integral macro scale $(L)$ is the largest scale and reflects the size of turbulent eddies. Its length is affected by the system boundary such as the piston height for IC engine environment. The Kolmogorov scale $\left(l_{K}\right)$ is the smallest scale and reflects the size of the vortex tube. In presented model, the burning time of such small length is assumed to be instantaneous. The third scale is Taylor microscale $\left(\lambda_{m}\right)$ which is the universe size of small cells inside the integral eddies. This scale is important to the combustion model since its size reflects the turbulent condition and affects the eddy burning time. The length of microscale has been defined as a function of integral scale and Reynolds number.

Blizard and Keck [6] developed the original turbulent entrainment model. The flame propagation speed $u_{e}$ is assumed slowly varying and the mass burned rate is derived with assumption of exponential eddy burning time, as shown in equations (1) and (2). The flame geometry is assumed as spherical surface. The flame area and volume are expressed as integrals of circle length and area of transversal surface with chamber height. The expression of mass burned fraction is finally obtained by solving first order 
differential equations including (1), (2), flame geometry expressions and a thermodynamic model.

$$
\begin{gathered}
\dot{m}_{f}=\rho_{u} A_{f} u_{e} \\
m_{b}=\int_{0}^{t}\left(1-e^{-\left(t-t^{\prime}\right) / \tau}\right) \rho_{u} A_{f} u_{e} d t^{\prime}=m_{f}-\tau \dot{m}_{b}
\end{gathered}
$$

Tabaczynski, et al. [7] modify their previous combustion model. The mass entrainment speed $\left(u_{e}\right)$ is proportionally related to the turbulent intensity which is derived as a function of unburned mass density $\left(\rho_{u}\right)$ during the combustion. Then the eddy entrainment speed is expressed as function of mass density as shown in equation (3). They also give a detail solution to calculate the eddy burning time $\left(\tau_{b}\right)$ according to the single eddy burning process.

$$
u_{e}=u_{e, r}\left(\frac{\rho_{u}}{\rho_{u, r}}\right)^{1 / 3}
$$

In [8], they refine their model by adding laminar flame speed term in the flame entrainment speed $\left(S_{L}\right)$ in equation (4). They also modify the eddy burning time as the microscale length divided by laminar flame speed shown as equation (5). That is because the expression they solved in the previous work does not work well to express the eddy burning time during the procedure of flame development and the flame propagation might be in developing state for most of the combustion. The predicted MFB results from the refined model match well with experimental data under different conditions of EGR, lambda and spark time.

$$
\dot{m}_{e}=\rho_{u} A_{f}\left(u^{\prime}+S_{L}\right)
$$




$$
\tau=\frac{\lambda}{S_{L}}
$$

Beretta, Rashidi and Keck [13] add a laminar burning term in the mass burning rate calculation shown in equation (6) since they have observed the dependence of the burning rate on the laminar flame speed in the early combustion stage. Then, one of the authors Keck [5] modifies this model by adding a exponential term in the turbulent part of mass entrainment rate calculation. The modified expression of mass entrainment rate is shown as equation (7). This exponential term is to describe the initial growth of the flame before the first eddy close to ignition site is burned. The time constant $\tau_{1}$ represents burning time of the first eddy.

$$
\begin{gathered}
\dot{m}_{b}=\rho_{u} A_{f} S_{L}+\frac{m_{e}-m_{b}}{\tau_{b}} \\
\dot{m}_{e}=\rho_{u} A_{b} u_{T}\left(1-e^{\frac{-t}{\tau_{1}}}\right)+\rho_{u} A_{b} S_{L}
\end{gathered}
$$

Ayala $[1,9]$ uses the above modified model in his research. In his dissertation he also express the exponential term of early flame growth with flame radius scale instead of time scale, and he get better results. In addition he uses turbulent intensity as the main turbulent entrainment speed and tries different correlations which express that as functions of mass density $\left(\rho_{u}\right)$. The model implemented in this report is based on this model, so more details will be introduced in the next chapter.

\subsection{TWO-ZONE HEAT RELEASE MODEL}

The turbulent propagation model considers physical variables of burned and unburned gas. Variables such as in-cylinder pressure, mass density and temperature are necessary 
to solve the equations and to calculate other combustion variables such as turbulent intensity and laminar flame speed.

Guezennec, et al. [10] use the two-zone (burned and unburned zones) model to predict variables during combustion with in-cylinder pressure data. The model covers the process from the intake valves closing to exhaust valves opening. Both of the burned and unburned zones have their individual temperature, mass and volume, but the pressure is same all around the chamber. The heat transfer to the chamber wall or piston is considered and it is assumed no heat transfer between two zones. As a result this twozone model predicts more reasonable mass fraction burned values and it makes more variables are available to be accessed. Yeliana, et al. [14] compares the performance of single-zone and two-zone heat release models in an ethanol and gasoline blended fuel engine. Both heat transfer and crevice volume factors are considered in the models.

\subsection{CYCLIC VARIATION IN ENGINE COMBUSTION}

Cycle-to-cycle variation exits in the combustion process as presented in real engine tests. This variation is more severe under lean or diluted conditions.

Rashidi [15] studies the cycle-to-cycle variation with photographs taken from a transparent piston engine. A period from the spark occurrence to a formed stabilized flame kernel is observed and defined as ignition delay. From the observation, the variations of both the length of the period and the time of its formation exist among consecutive combustion cycles. The shapes of flame fronts right after the stabilized flames are different due to the variation of the flow velocities. It is also concluded that the length of this flame stabilization period could be influenced by the turbulent structure, and it is also the major cause of cyclic variation of the combustion process. The variation of the main part of the flame propagation is also affected by the turbulent velocity and structure. 
Keck et al. [5] study the early flame development process with an optical combustion chamber piston engine. From the observation of several combustion tests, it is found that the real flame kernels have random locations around the spark plug and their distribution has different trends under different mixtures of flow conditions. The authors conclude that the randomness of the early flame kernel is one of the major causes of the cyclic combustion variation. Also, the variations of burning speed and the first eddy size after ignition play the essential roles to the fluctuation of early stage combustion. The initial burning speed is mainly laminar flame speed and it is affected by the mixture situation near the spark site. The variation of first eddy size is caused by the fluctuation of turbulent structure of each cycle.

Aghdam et al. [16] summarize several cyclic variation sources and include the fluctuation of turbulent flow into their combustion model. The cyclic variations of engine combustion could be easily observed from in-cylinder pressure, combustion phasing and combustion duration. However, the origins of cyclic variations may come from (1) the turbulent intensity, (2) engine inputs (lambda, air flow, et al), (3) the mixture composition near the spark plug and (4) the spark ignition process. The authors observe the peak pressure versus peak pressure location (crank angle) scatters and their distributions comparing with those from engine data. By adjusting the variation level of the turbulent fluctuations, the model could simulate engine outputs with similar variations to those of experimental data. 


\section{MEAN-VALUE FUNDAMENTAL COMBUSTION MODEL FOR SPARK-IGNITION ENGINE}

In this chapter, a fundamental combustion model is implemented combining with twozone thermodynamic model. The predicted results of the model are compared with engine test data recorded by ACAP data acquisition system developed by the DSP Technology Inc. It is used for a Ford Ecoboost 3.5L V6 DI gasoline engine. The performance of the model is tuned by changing some model parameters and unmeasured engine inputs.

\subsection{MODEL DESCRIPTION}

The fundamental combustion model presented in this report is a turbulent propagation and eddy burning model to predict the mass burned rate. Unlike some of the early works that are achieved by solving differential equations, the presented model is achieved by writing in discrete form with basic Euler integral method. No iterations are needed to improve the solution. Besides, the variables of unburned gas are predicted with two-zone thermodynamic model and the geometry of flame is assumed spherical with growing radius.

\subsubsection{TURBULENT ENTRAIMENT AND EDDY-BURN MODEL}

The turbulent entrainment model described in [9] is employed. The turbulent flame entrains the unburned gas from a spherical surface with the rate related to the laminar flame speed and turbulent intensity. Unburned gas in or out of flame has turbulent structure, so it can be described with the three characteristic lengths. The unburned gas entrained into the flame will be burned with laminar flame speed in the unit of microscale length $\left(\lambda_{m}\right)$. Equations (8) to (10) are the expressions of the combustion model.

$$
\frac{d m_{e}}{d t}=\rho_{u} A_{e}\left[S_{L}+u^{\prime}\left(1-e^{\frac{-t}{\tau_{1}}}\right)\right]
$$




$$
\begin{gathered}
\frac{d m_{b}}{d t}=\rho_{u} A_{e} S_{L}+\frac{m_{e}-m_{b}}{\tau_{b}} \\
\tau_{b}=\frac{\lambda_{m}}{S_{L}}
\end{gathered}
$$

Equation (8) is the expression of entrainment mass $\left(m_{e}\right)$ rate which contains a laminar burning component $\left(S_{L}\right)$ and a turbulent propagation one $\left(u^{\prime}\right)$. The unburned mass density $\left(\rho_{u}\right)$ multiplies by the entrained flame front area $\left(A_{e}\right)$ represents the entrained volume of each step. The turbulent propagation component is multiplied by an exponential term to describe the development of early flame growth of the combustion cycle. The value of the exponential term increases from zero to full turbulent intensity. With a time constant $\left(\tau_{1}\right)$ defined as burning time of the first eddy after ignition. As shown in Figure 3.1, the turbulent intensity reaches around $2 / 3$ of full scale at time equal to the time constant $\tau_{b}=10$. The shorter the time constant is, the quicker the turbulent propagation dynamics is. In the presented model, the time constant is chosen one fifth of the original value which results in much quicker exponential term. The value of this time constant affects the flame propagation speed significantly. However, the definition of this parameter is not firmly defined in previous research. So, it will be a tunable parameter for the presented model. The selection of this parameter's value will be discussed in the model calibration section. 


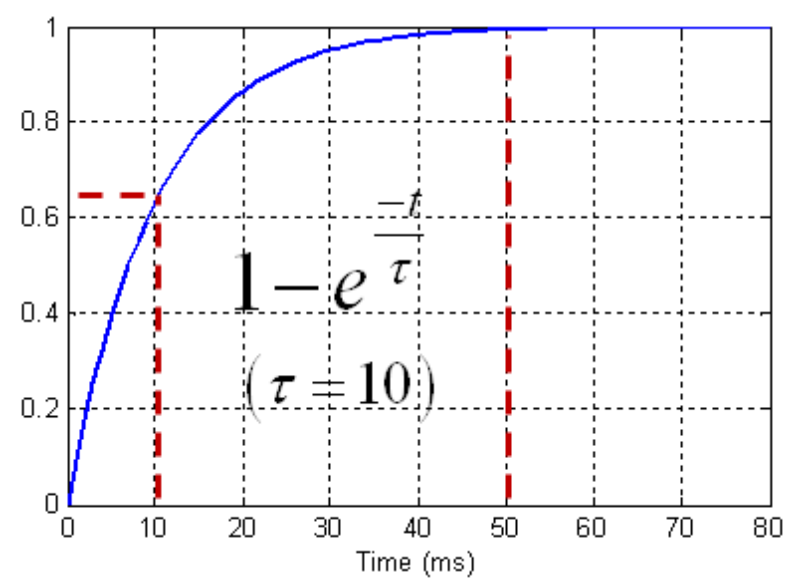

Figure 3.1: Growing of exponential term with time constant of $10 \mathrm{~ms}$

Equation (9) describes the calculation of burned mass $\left(m_{b}\right)$ rate. The first component is the laminar mass burning occurred in front of the flame surface. The second component, which is the major part, represents the burning of unburned gas entrained by the flame. The denominator is the characteristic time $\left(\tau_{b}\right)$, the eddy burning time expressed by equation (10). The definition of the eddy burning time is the time to burn up a single cell of Taylor microscale length $\left(\lambda_{m}\right)$ with laminar flame speed $\left(S_{L}\right)$. The ratio of the entrained unburned mass $\left(m_{e}-m_{b}\right)$ to the eddy burning time is the component of mass burned rate inside the entrained gas fuel mixture.

\subsubsection{COMBUSTION VARIABLES}

From the description of combustion model, it is clear that the mass burning rate is estimated by modeling the turbulent movement and eddy burning process. To accomplish this model the correlations of the variables including laminar flame speed, turbulent intensity and turbulent microscale length need to be known. The values of these variables changes as the environmental condition changes. Their relations have been derived and summarized from experimental observation of combustion by many researches. In this section the correlations of these variables used in the presented model are introduced. 


\subsubsection{LAMINAR FLAME SPEED}

The speed of laminar flame is comparatively easier to detect from combustion experiments in laminar conditions. This is because the propagation of laminar is smoother comparing with turbulence and it basically traces the radial direction of combustion. There are many forms of expressions of laminar flame speed with environmental variables. For the presented model, the form presented by Rhodes and Keck [2] is used and introduced here.

The value of laminar flame speed usually depends on environmental condition including temperature $\left(T_{u}\right)$, pressure ( $p$ ), fuel type and diluted level (lambda, egr or res ). Rhodes and Keck [2] gave the expression of laminar flame speed as equation (11).

$$
S_{L}=S_{L 0}\left(\frac{T_{u}}{T_{0}}\right)^{\alpha}\left(\frac{p}{p_{0}}\right)^{\beta} f_{n}(r e s)
$$

In the expression, $T_{0}$ and $p_{0}$ are temperature and pressure of reference condition and their values are chosen as $298 \mathrm{~K}$ and $101 \mathrm{kPa}$ respectively. The laminar flame speed in the reference condition $\left(S_{L 0}\right)$ relates to equivalence ratio (ratio of actual AFR to stoichiometric AFR) and fuel type. The values of $S_{L 0}, \alpha$ and $\beta$ are modeled from the fitted curves of experimental data versus equivalence ratio. Their expressions are shown in equations (12)-(14). The coefficients in equation (12) and the forms of equations (13) and (14) are specific for gasoline engine condition.

$$
\begin{gathered}
S_{L 0}=30.5-54.9(\phi-1.21)^{2} \\
\alpha=2.4-0.271 \phi^{3.51} \\
\beta=-0.357+0.14 \phi^{2.77}
\end{gathered}
$$


The last term in equation (11) is a function of fuel diluted fraction. In study [2] a distinct correlation between laminar flame speed and diluents fraction is observed from experimental tests with different equivalence ratios and environmental conditions. The

expression of $f_{n}$ for gasoline combustion condition is shown in equation (15). The variable res in (15) is percentage of exhaust diluents gas including both residual gas fraction and exhaust gas recirculation (EGR).

$$
f_{n}=1-2.06 \mathrm{res}^{0.733}
$$

\subsubsection{TURBULENT INTENSITY}

Turbulent intensity is considered as the main component of flame propagation speed and has significant influence in the gas entrainment and burning rate. Turbulent flow is more complicated than laminar one and it is more difficult to observe its relation to environmental variables. In the presented model, the turbulent flow is assumed having no specific direction (isotropic) in the engine combustion chamber.

The turbulent intensity expression in equation (16) is used papers [1] and [7]. The subscript 0 represents the variables at time of ignition. The turbulent intensity after ignition is a function of unburned mass density. This expression is derived from the conservation of angular momentum of individual integral eddy derived by equation (17) .where the large eddy length scale $(L)$ is expressed as function of unburned mass density.

$$
\begin{aligned}
& u^{\prime}=u_{0}^{\prime}\left(\frac{\rho_{u}}{\rho_{u 0}}\right)^{\frac{1}{3}} \\
& L=L_{0}\left(\frac{\rho_{u 0}}{\rho_{u}}\right)^{\frac{1}{3}}
\end{aligned}
$$


The initial turbulent intensity $u_{0}^{\prime}$ was assumed to be proportional to the mean piston speed in the model introduced in [8]. However, Keck [3] summarized the relation of initial turbulent intensity expressed as equation (18) with groups of experimental data. In equation (18) the initial turbulent intensity is a function of the mean piston speed $\left(\overline{u_{p}}\right)$ and the ratio of unburned mass density to the mass density of inlet gas (mass density after intake valve closing). After implementing this equation into the presented model, it is found that the root square term in equation (18) may not be appropriate comparing with Ecoboost data. To provide the flexibility of the developed model, the parameter $C$ and the order of the density ratio are adjustable for the model calibration.

$$
u_{0}^{\prime}=C \cdot \bar{u}_{p} \cdot\left(\frac{\rho_{u 0}}{\rho_{\text {in }}}\right)^{\frac{1}{2}}
$$

\subsubsection{TURBULENCE MICROSCALE LENGTH}

The turbulence microscale length also called Taylor microscale length $\left(\lambda_{m}\right)$ illustrates the size of dissipative cells in turbulent eddies. In the combustion model, the value of microscale length is necessary for the calculation of eddy burning time in equation (10). Tennekes [17] gives the definition of the ratio of Taylor microscale length to turbulent integral length $(L)$ as a function of Reynolds number $\left(\operatorname{Re}_{t}\right)$ in equation (19).

$$
\begin{aligned}
\frac{\lambda_{m}}{L} & =C \cdot \mathrm{Re}_{t}^{-0.5} \\
\operatorname{Re}_{t} & =\frac{\rho_{u} u^{\prime} L}{\mu}
\end{aligned}
$$

Equation (20) is the definition of Reynolds number for gas flow in the engine combustion chamber. The velocity of flow is represented by turbulent intensity $u^{\prime}$ and the characteristic dimension is represented by turbulence integral length $(L)$. The dynamic 
viscosity of flow $(\mu)$ is related to environmental temperature. Substituting the expressions of turbulent intensity after ignition in equations (16) and (17) and assuming that the integral length is proportional to the chamber height $h(\theta)$, the microscale length could be expressed as equation (21). The subscript 0 represents the parameter values at spark ignition. Constant $C^{\prime}$ is an adjustable parameter for model calibration.

$$
\begin{aligned}
\lambda_{m} & =C \cdot \operatorname{Re}_{t}^{-0.5} \cdot L=C \cdot\left(\frac{\mu L}{\rho_{u} u^{\prime}}\right)^{\frac{1}{2}} \\
& =C^{\prime} \cdot\left(\frac{\mu \cdot h_{0}}{u_{0}^{\prime}}\right)^{\frac{1}{2}} \rho_{u 0}^{\frac{1}{3}}\left(\frac{1}{\rho_{u}}\right)^{\frac{5}{6}}
\end{aligned}
$$

\subsubsection{FLAME GEOMETRY}

In the presented model, the flame front is assumed spherical surface based on the conclusions of several experimental observations without swirl ([3], chapter 9 of [12]). Many researchers (discussed in literature review) have built their combustion models with such assumption. The ignition locates in the center of cylinder head for Ford Ecoboost gasoline engine. For the purpose of simplified calculation the electrodes of spark plug are assumed just in the plane of the cylinder head in the model. The radius of the flame propagates with the same speed as gas entrainment speed: laminar burning speed and turbulent intensity with exponential development factor at early stage. The flame entrained area and volume will be calculated with semi-spherical surface and volume equations (22) and (23).

$$
A_{\text {semi-sphere }}=2 \pi r^{2}
$$




$$
V_{\text {semi-sphere }}=\frac{2}{3} \pi r^{3}
$$

For the condition in engine combustion chambers, since combustion starts close to the top dead center (TDC), the flame front will reach the piston head firstly and then chamber wall while propagating. The process of flame geometry development is shown in Figure 3.2. Figure 3.2 (a) is the early stage of flame formation and the flame is half of sphere. From the observation of early flame formation in [5] the shape of flame at that stage covers around the spark plug and is equivalent to sphere. Due to the small area or volume of the flame at this stage, is does not induce much changes of in-cylinder pressure and heat release. Soon after the ignition the flame will reach piston head as shown in Figure 3.2 (b) and it will mainly propagate along with the radial direction until reaching the chamber wall shown in Figure 3.2 (c). During (b) and (c) stages, the flame shapes are partial semi-spheres and the calculations of their surface areas and volumes are shown in equations (24) and (25). For the condition of (c) the flame is not only "cut" from bottom but also side. At the end of propagation, the flame fully fills the combustion chamber as shown in Figure 3.2 (d). The flame front area becomes zero and the volume becomes the maximum. Usually, the energy released from combustion increases the most quickly during this period. 


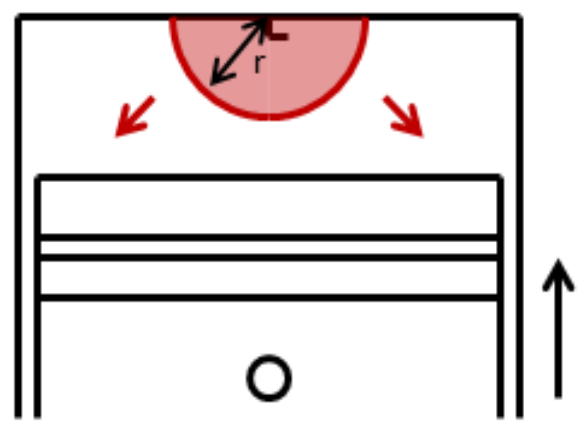

(a)

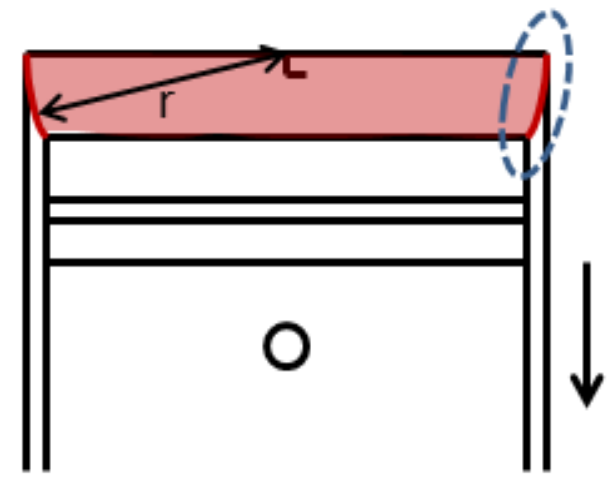

(c)



(b)

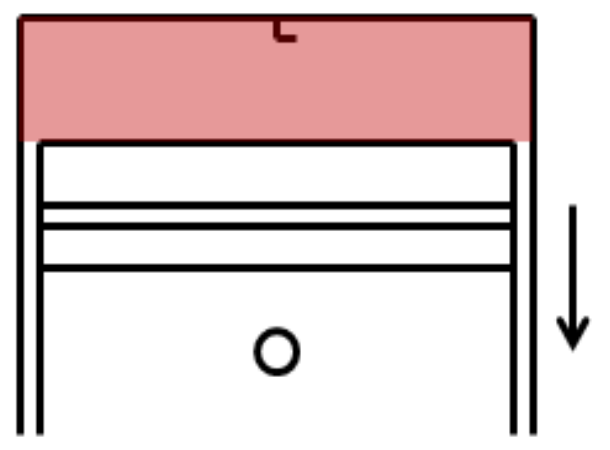

(d)

Figure 3.2: Flame geometry propagation process in engine combustion chamber, (a) the early state, (b) flame front reaches piston head, (c) flame front reaches cylinder wall, (d) flame and burned gas fully fill the combustion chamber.

$$
\begin{gathered}
A_{\text {partial-sphere }}=2 \pi r h \\
V_{\text {partial-sphere }}=\pi r^{2} h-\frac{1}{3} \pi h^{3}
\end{gathered}
$$

The intersection between flame and chamber wall is considered not only for the flame geometry aspect but also for the contact area between flame and chamber wall (including cylinder head and piston). The amount of energy from heat transfer to chamber wall or 
piston is closely related to the contact area, the detail will be discussed in the next section. The method to calculate contact area is apparent after determining the geometry of combustion flame. It is needed to mention that when the flame fully fills the chamber in stage (d), the contact area will be the inner surface area of the combustion chamber.

\subsubsection{TWO-ZONE THERMODYNAMIC MODEL}

To implement the fundamental combustion model, some thermodynamic variables in the combustion chamber need to be determined. A two-zone thermodynamic model is used to determine the values of these variables, including mass density, in-cylinder pressure and temperature. This model is based on the First Law of thermodynamics in equation (26) and ideal gas law in equation (27).

$$
\begin{gathered}
d U=\delta Q-\delta W \\
p V=m R T \text { or } p=\rho R T
\end{gathered}
$$

When the intake valve closes, the value of gas mass density is related to the pressure and temperature of intake manifold which are the inputs of combustion model. The first stage is the polytropic process between the intake valve closing and ignition occurrence. The whole stage takes place in the compression stroke and energy exchanges only by heat transferring from chamber wall. The in-cylinder pressure is estimated with apparent heat release formula in equation (28) which is derived from the first law in equation (26).

$$
\delta Q=\frac{\gamma}{\gamma-1} p \cdot d V+\frac{1}{\gamma-1} V \cdot d p
$$

The energy change $\delta Q$ is composed of chemical heat release from combustion and heat transfer to chamber wall. In the stage before ignition there is no chemical heat release and only heat transfer effect of unburned zone is counted. The heat capacity ratio $\gamma$ is the adiabatic index. Heat transfer is already considered in the apparent heat change $(\delta Q)$, 
otherwise the heat capacity ration $(\gamma)$ value in equation (28) could be replaced by polytropic coefficient which is usually smaller.

The estimation of heat transfer amount of each crank angle step is expressed in equation (29) according paper [5]. The direction of heat transfer calculated by equation (29) is from unburned gas to chamber wall. Since this model is crank angle-based, engine speed $(N)$ needs to be considered to convert from time-based equation. The heat transfer constant $h_{h t}$ could be determined from Woschni's work [18] in equation (30).

$$
\begin{aligned}
& d Q_{h t}=A_{\text {contact }} h_{h t}\left(T-T_{\text {wall }}\right) / N \\
& h_{h t}=C_{h t} \cdot d^{-0.2} \cdot p^{0.8} \cdot w^{0.8} \cdot T^{-0.53}
\end{aligned}
$$

In equation (30), $d$ is the characteristic length and it is engine cylinder bore length here, $p$ and $T$ are in-cylinder pressure and temperature respectively, $w$ is the characteristic speed and the mean piston speed is used. The constant $C_{h t}$ is an adjustable parameter for model calibration. Woschni gave a value of 110 for parameter $C_{h t}$ as recommendation. However, due to the different usage of $h_{h t}$ (divided by engine speed in the present model), its value should be in various scales. The detail of tuning this parameter will be discussed in the model calibration section.

The second stage starts from ignition and ends with the opening of exhaust value. The second stage ends when all chemical energy releases out. Without more chemical heat release, it returns to polytropic process in the cylinder like the first stage. The model of this stage is considered two-zone: burned and unburned zone as shown in Figure 3.3. The two-zone model follows the first law of thermodynamics and the fuel loss in crevice is not considered. 


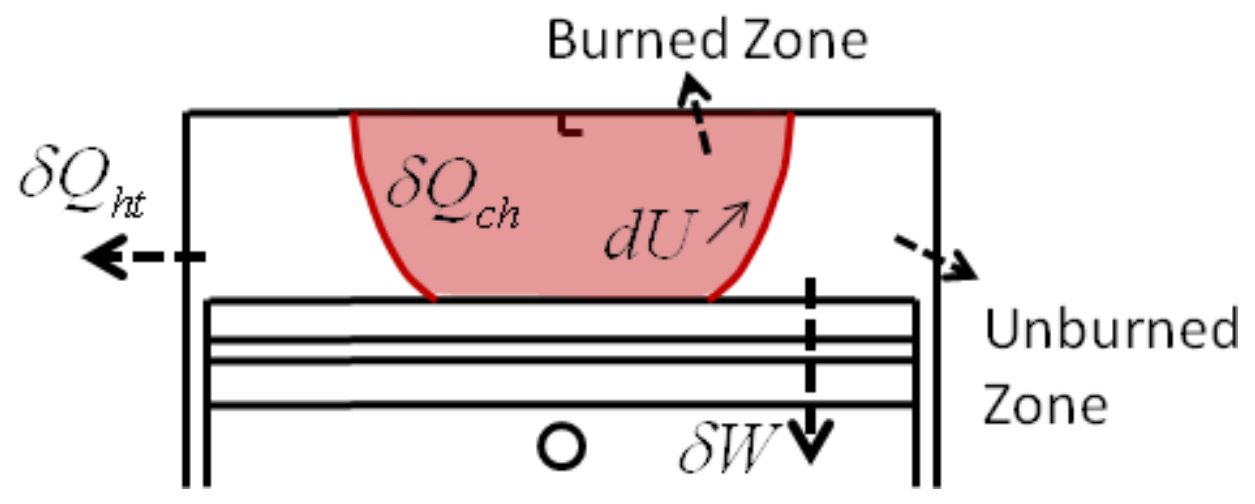

Figure 3.3: Schematic diagram of two-zone combustion thermodynamic model.

The two zones have differences in all states except with the same pressure during all time. The value of unburned mass density is necessary for the estimation of flame propagation and mass burned rate in equations (8) and (9). Pressure and temperature in unburned area are also needed for the estimation of other variables in combustion. Temperature in burned area could be used to approximate determine the heat capacity information $\left(c_{p} c_{v} \gamma\right)$. Equation (31) is the expression of energy distribution of two-zone model based on first law of thermodynamics in equation (26).

$$
\begin{aligned}
& m_{b} c_{v b} d T_{b}+m_{u} c_{v u} d T_{u}+\delta m_{b}\left(c_{v b} T_{b}-c_{v u} T_{u}\right)=\frac{\delta m_{b} Q_{L H V} \cdot \eta_{c}}{A F R} \\
& -\left[A_{u} h_{h t, u}\left(T_{u}-T_{\text {wall }}\right)+A_{b} h_{h t, b}\left(T_{b}-T_{\text {wall }}\right)\right] / N-p d V
\end{aligned}
$$

$b$ and $u$ in the subscripts represent variables in burned and unburned zones, respectively. The left side of equation (31) is the internal energy change of one discrete step for the whole chamber. The third term represents the internal energy change of the burned mass in current step. In the right side, the first term is the chemistry energy released from the fuel with a combustion efficiency term $\left(\eta_{c}\right)$. All the mass variables in the model are mass of gas mixture without fuel because it is hard to trace the mass density with direct injection (DI) fuel delivery method as Ecoboost has, and the injection time and vaporization percentage are not considered. That is the reason that only air fuel ratio 
(AFR) is listed in the denominator of first term in the right. Second term is the heat transfer amount of both zones and the expression has been discussed previously.

The mass densities of both zones are hard to estimate during the early combustion. The mass and volume of burned gas are small so the part between burned gas and flame front could not be neglected. To find approximate value of unburned mass density, equation (32) which is derived from features of adiabatic process is used. Temperature of unburned zone can be calculated accordingly with ideal gas law in equation (27). Then only one variable which is the temperature of burned zone is unknown in equation (31).

$$
\frac{p_{2}}{p_{1}}=\left(\frac{\rho_{2}}{\rho_{1}}\right)^{\gamma}
$$

The volume of burned zone is assumed the same as the spherical flame volume with the calculation method described in previous section. One limitation is that the area between the burned and unburned zones (entrained in flame and not burned) is not considered. As studied by Keck [3], there is small difference between the burned surface and the flame surface which depends on the turbulent microscale length. In the presented model, they are assumed the same for simplification since there is no rigid accuracy requirement in the estimation of the geometries of two zones.

\subsection{MODEL CALIBRATION}

The parameters of combustion model need to be adjusted to predict proper output values that fit to experimental results under specific engine combustion condition. Increase the number of adjustable parameters increases the degree of freedom and also the difficulty of the model tuning.

\subsubsection{MODELING \& CALIBRATION ENVIRONMENT}


The presented combustion model is written in SIMULINK graphical programming environment for ease of modification and calibration. The MATLAB/SIMULINK has strong computational power and user friendly interface for parameterization and programming. The inputs of engine operation and the parameters of engine model are defined in an initial MATLAB .m file. The experimental data acquired by ACAP system are logged and loaded as .mat data file into MATLAB workspace. These experimental data are used as a base for the calibration of model parameters. The combustion .mdl file in SIMULINK can be integrated with other sub-systems of vehicle or control strategies for engine or vehicle tests.

\subsubsection{ENGINE AND OPERATING PARAMETERS USED IN SIMULATION}

Table 3.1 lists the engine information and operating conditions used for simulation. The left column contains the engine specific information and the right column gives the values of operating variables. The "Res (\%)" represents the percentage of residual gas fraction. The residual gas is the gases that remain in the cylinder after the exhaust stroke has been completed and the recirculated gas from intake pipe during the overlap between intake valve opening and exhaust valve closing. Unlike EGR value, the residual gas fraction cannot be measured from oxygen sensors mounted on intake and exhaust pipes. Fox [19] gives the estimation method for the residual gas fraction of a gasoline engine. However, some of parameters for the estimation are not available yet. The value of $15 \%$ is assumed in the simulation. The values of lower heating value (LHV) and AFR at stoichiometric condition are selected as those values provided in the appendix of Heywood's book [12]. The temperature of chamber wall is chosen based on the average values of engine dyno test data. The temperature of inlet gas ( $T$ _ inlet) influences the total mass amount taken into the combustion. Its value is presumed based on the in-cylinder pressure matching with experimental results. 
Table 3.1: Engine information and operating conditions used for simulation

\begin{tabular}{|c|c|c|c|}
\hline Clearance Volume & 0.5827 & Res $(\%)$ & 15 \\
\hline Bore $(\mathrm{mm})$ & 92.5 & LHV $(\mathrm{KJ} / \mathrm{g})$ & 44 \\
\hline Stroke $(\mathrm{mm})$ & 86.7 & AFR $($ stoi) & 14.6 \\
\hline Compression Ratio & 10 & T_inlet $(\mathrm{K})$ & 338 \\
\hline Spark Plug Position & central & T_wall (K) & 360 \\
\hline
\end{tabular}

\subsubsection{CALIBRATION OF MODEL PARAMETERS}

The combustion model parameters that need to adjust are listed in Table 3.2. Initial values of these parameters are selected for the combustion simulation. The simulation results are compared with engine test data from Ford Ecoboost 3.5L V6 gasoline engine to find appropriate set of parameter values. The major outputs need to be matched are the in-cylinder pressure and mass fraction burned (MFB). The experimental MFB values are estimated from engine pressure data by two-zone model in equation (28). Additional combustion metrics such as CA50 (crank angle degree at 50\% MFB), $0 \sim 10 \%$ and $10 \sim 90 \%$ burn durations are also required to be properly predicted. 
Table 3.2: Adjustable model parameters

\begin{tabular}{|c|c|}
\hline Parameters & Expression/Description \\
\hline const $_{1}$ & $u_{0}^{\prime}=\operatorname{const}_{1} \cdot \overline{u_{p}} \cdot\left(\frac{\rho_{u}}{\rho_{i n}}\right)^{\text {ind }_{u^{\prime}}}$ \\
\hline const $_{u^{\prime}}$ & $\lambda_{m}=$ const $_{2} \cdot\left(\frac{\mu \cdot h(S I)}{u_{0}^{\prime}}\right)^{\frac{1}{2}} \rho_{u 0}^{\frac{1}{3}}\left(\frac{1}{\rho_{u}}\right)^{\frac{5}{6}}$ \\
\hline$n_{\tau}$ & $\frac{d m_{e}}{d t}=\rho_{u} A_{e}\left[S_{L}+u^{\prime}\left(1-e^{\frac{-t}{\tau_{b} / n_{\tau}}}\right)\right]$ \\
\hline$C_{h t}$ & $h_{h t}=C_{h t} \cdot B^{-0.2} \cdot p^{0.8} \cdot \bar{u}_{p}^{0.8} \cdot T^{-0.53}$ \\
\hline$\gamma_{c} \gamma_{e}$ & Heat capacity ratios of compression and \\
\hline$\eta_{c}$ & Cxpansion strokes \\
\hline
\end{tabular}

\section{CALIBRATION OF PARAMETERS: const $_{1}$ AND const $_{2}$}

The MFB values are sensitive to the turbulent intensity and microscale length. The related parameters could be calibrated based on how well the simulation results match to the engine test results. Parameters const $_{1}$ and const $_{2}$ are the most direct factors to influence the turbulent intensity and microscale length. The secondary important parameters, $i n d_{u^{\prime}}$ is initially chosen to be $1 / 3$ as recommended in [3] and $n_{\lambda}$ is chosen to be 5 as discussed earlier.

The predicted curves of entrained mass and burned mass versus crank angle during combustion for one test are shown in Figure 3.4. The entrainment process ends when the 
flame fully fills the combustion chamber. At this moment some of mixture entrained in flame is still burning with laminar flame speed. So the burned mass reaches the final value later than the entrained mass.

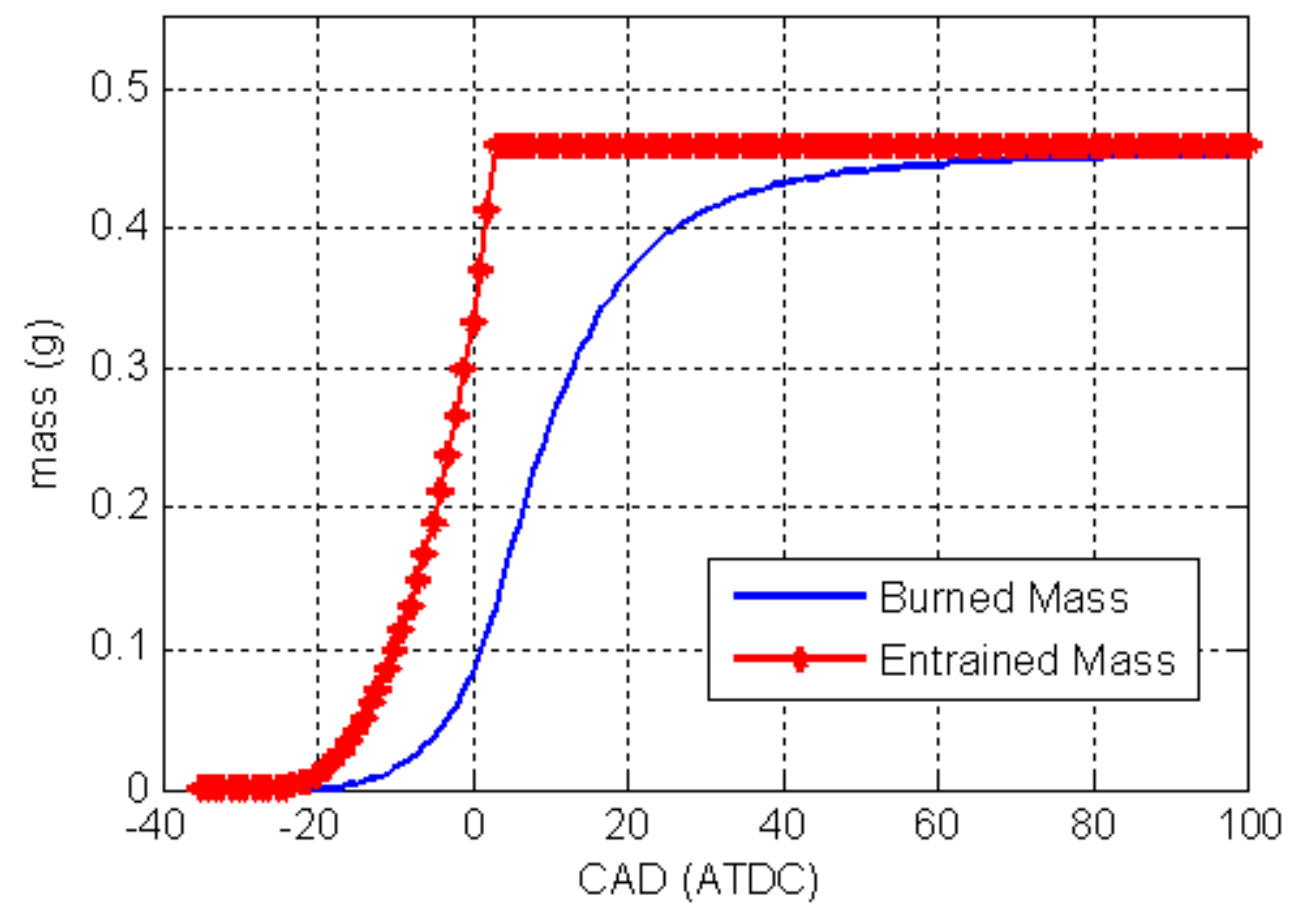

Figure 3.4: Entrained and burned mass history during combustion by simulation, 2000 rpm, 5 bar BMEP, lambda $=1$, MBT

The parameter const $t_{1}$ influences the phase of the entrained mass curve since the turbulent intensity is the major impact factor of the mass entrainment speed. Large turbulent intensity leads early completion of mass entrainment and indirectly advances mass burning curve. The parameter const $_{2}$ relates to the microscale length and the eddy burning time. Large microscale length results in long eddy burning time and the entrained mass will burn slowly. Usually, the mass burning has the maximum rate when the entrainment ends. This can be seen from the equation (9) since the largest difference between the entrained mass and burned mass occurs at the end of entrainment. So, the crank angle at end of entrainment could be or close to the maximum heat release rate 
point. Figure 3.5 (a) compares the simulated heat release rate during combustion with the experimental heat release rate curve which is estimated from pressure data. Figure 3.5 (b) compares the simulated het release with experimental result. The heat release values are the mean values of 300 consecutive combustion cycles.

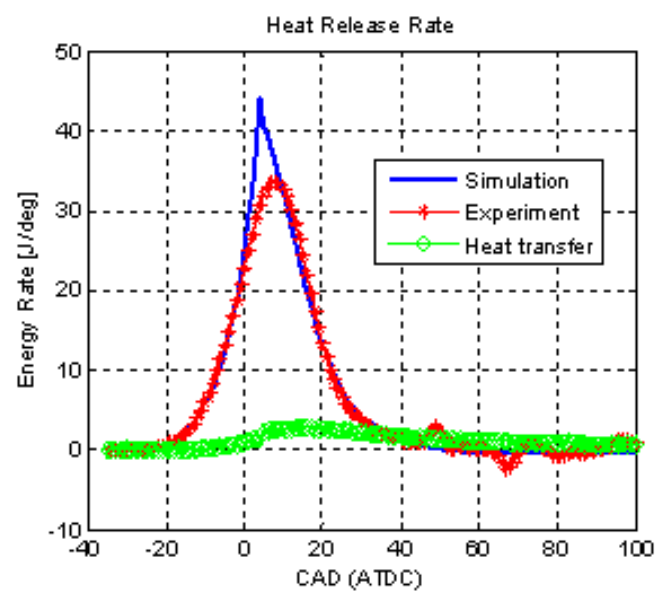

(a)



(b)

Figure 3.5: Predicted and experimental heat release rate and hear release data, $2000 \mathrm{rpm}$, 5 bar BMEP, lambda $=1$, MBT.

The simulated maximum heat release rate point is advanced comparing with that of experimental data. This may be caused by a sudden end of mass entrainment in the simulation. In addition, unable to simulate the trend of mass burning rate correctly after the entrainment ends could be another reason to cause this mismatch. The simulated heat release curve is close to the experimental result as shown in Figure 3.5 (b).

\section{CALIBRATION OF GAMMA, $C_{h t}$ AND $\eta_{c}$}

To appropriately predict heat release, the acceptable in-cylinder pressure data are needed. If the heat release information is successfully simulated but there is an apparent difference between the simulated in-cylinder pressures and experimental data, it means 
that some parameters related to total released energy are not well chosen. The parameters related to total released energy include combustion efficiency $\left(\eta_{c}\right)$, heat transfer $\left(C_{h t}\right.$ $\left.T_{\text {wall }}\right)$, inlet gas temperature $\left(T_{i n}\right)$ and heat capacity ratio $\left(\gamma_{c} \gamma_{e}\right)$.

The combustion efficiency can be referred from figure 3-9 of Heywood's book [12] as a function of equivalence ratio for gasoline engine. The heat capacity ratio (gamma) of adiabatic process generally depends on the temperature and composition of gas mixture. The gamma value in compression stroke can be adjusted by the pressure curve before spark ignition. In expansion stroke, the value is lower due to high temperature and more product of combustion in the mixture. The amount of heat transfer can be referred from some universal energy distributions for general gasoline engines, for example, on page 27 of [20]. The temperature of inlet gas is a direct parameter to predict the overall amount of gas mass for each cycle. All these parameters need to be chosen to make in-cylinder pressure values close to experimental data while predicting reasonable intermediate variables. Figure 3.6 and Figure 3.7 show the energy distribution of one combustion cycle and predicted in-cylinder pressure predicted from simulation.

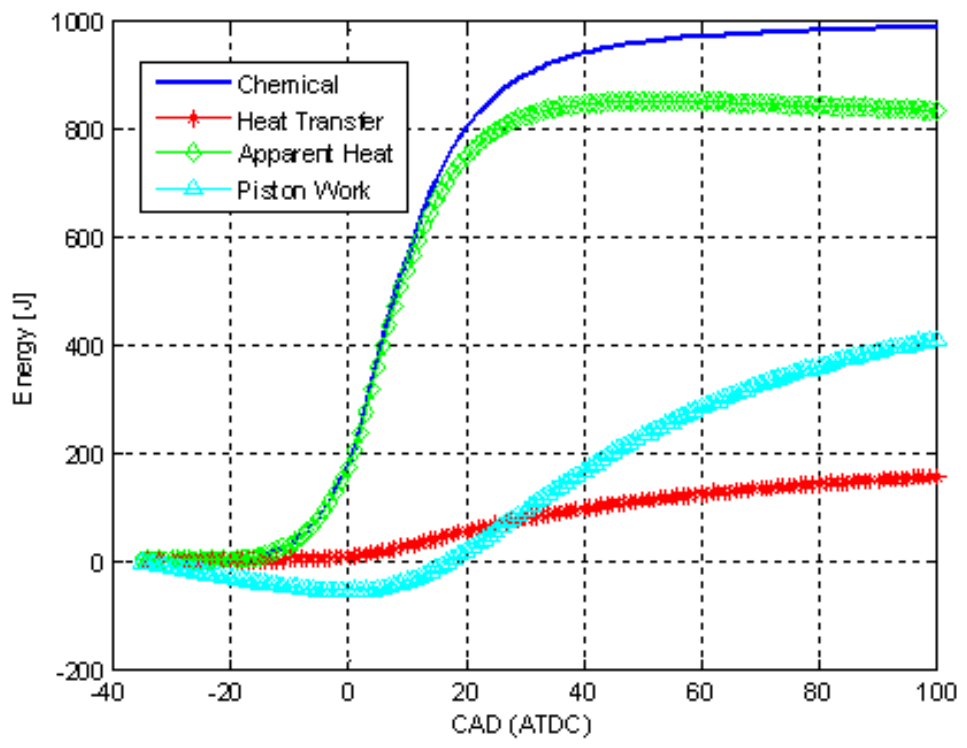

Figure 3.6: Energy distribution of one combustion cycle, $2000 \mathrm{rpm}$, 5bar BMEP, lambda $=1$, MBT. 


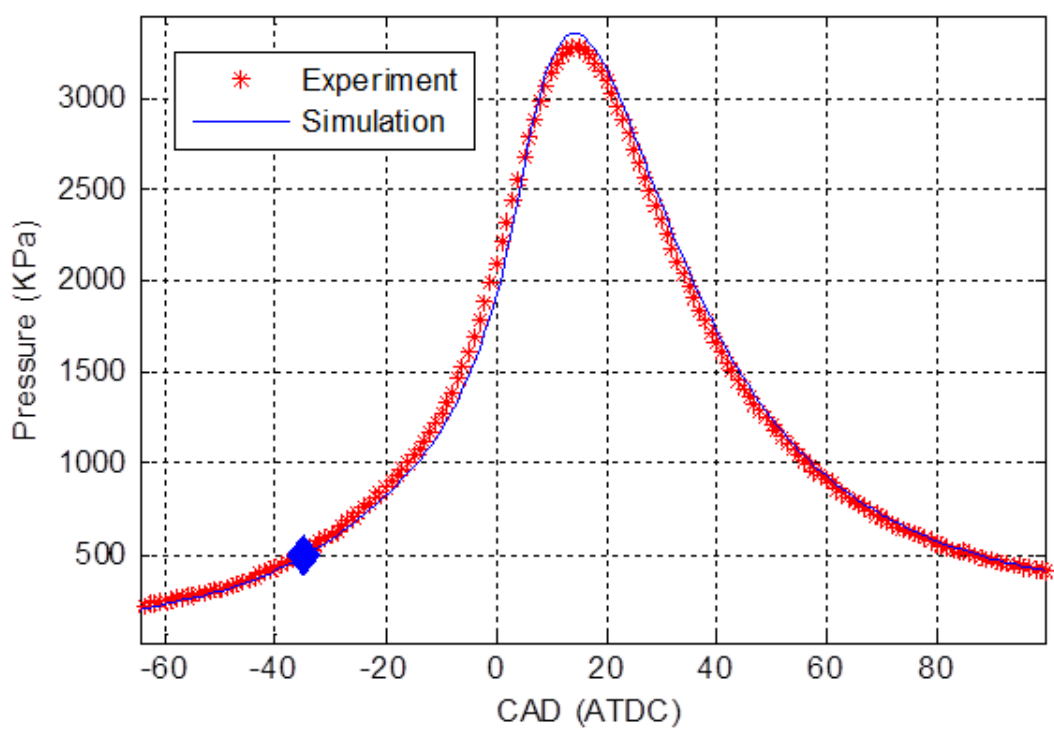

Figure 3.7: Predicted in-cylinder pressures vs. crank angle during combustion comparing with experimental results, $2000 \mathrm{rpm}, 5$ bar BMEP, lambda =1, MBT.

\section{CALIBRATION OF ind $_{u^{\prime}}$ AND $n_{\tau}$}

The additional tunable parameters are related to the rate of turbulence development process and the initial turbulent intensity at spark ignition. The parameters $i n d_{u^{\prime}}$ and $n_{\tau}$ (see in Table 3.2) have influences on these two aspects. Their values of these parameters are calibrated by fitting the simulation results with experimental ones in different operation conditions (speed, load, spark advance and lambda).

The parameter ind $_{u^{\prime}}$ is the order of the ratio of unburned mass density to mass density of inlet gas as shown in equation (18). Its value affects the turbulent intensity at the beginning of combustion. Based on comparison of simulation results with experimental data, the index ind $_{u^{\prime}}$ is calibrated to be $1 / 6$ to give proper prediction of heat release rate. The parameter $n_{\tau}$ is the denominator of the time constant in equation (8). Its value relates to the turbulence development rate. Theoretically, the developing turbulent 
intensity grows fully when the first eddy completes burning. As discussed previously, the value of $n_{\tau}$ is chosen to be 5 to speed up turbulent propagation.

\subsection{MODEL VALIDATION AND EXPERIMENTAL TEST RESULTS}

\subsubsection{ENGINE TEST MATRIX}

The simulation results, including predicted MFB and in-cylinder pressure values under different operation conditions are compared with experimental data to validate the model performance. The experimental data are collected from cylinder \#1 of Ford Ecoboost 3.5L V6 gasoline engine by in-cylinder pressure sensors and an ACAP combustion analyzer. The measured in-cylinder pressure data are relative change of pressure values, which to be "shifted" by referencing the absolute intake manifold pressure. The experimental heat release information is calculated from pressure data using equation (28).

Table 3.3: Matrix of operation conditions of engine tests

\begin{tabular}{|c|c|c|c|c|c|c|c|c|c|c|}
\hline $\begin{array}{c}\text { TEST } \\
\text { No. }\end{array}$ & RPM & $\begin{array}{c}\text { BMEP } \\
(\mathrm{bar})\end{array}$ & $\begin{array}{c}\text { MAP } \\
(\mathrm{KPa})\end{array}$ & $\begin{array}{c}\text { SA } \\
(\mathrm{dATDC})\end{array}$ & $\lambda$ & $\begin{array}{c}\text { EGR } \\
(\%)\end{array}$ & $\eta_{c}$ & $\begin{array}{c}\text { IVC } \\
(\mathrm{aBDC})\end{array}$ & $\gamma_{c}$ & $\gamma_{e}$ \\
\hline 1240 & 1500 & 2.62 & 45.9 & $-31(\mathrm{MBT})$ & 1.0 & 0 & 0.85 & 30 & 1.31 & 1.26 \\
\hline 1241 & 1500 & 2.62 & 42.0 & -17 & 1.0 & 0 & 0.85 & 10 & 1.31 & 1.26 \\
\hline 1254 & 1500 & 2.62 & 46.7 & -45 & 1.0 & 0 & 0.85 & 20 & 1.31 & 1.26 \\
\hline 1640 & 2000 & 5.0 & 66.4 & -35 & 1.0 & 0 & 0.88 & 10 & 1.31 & 1.26 \\
\hline 1647 & 2000 & 5.0 & 82.8 & -33 & 1.35 & 0 & 0.95 & 15 & 1.31 & 1.28 \\
\hline
\end{tabular}

Table 3.3 lists the engine test conditions for the validation of combustion model. The fourth column of table includes the values of intake manifold absolute pressure (MAP) 
which is an indication of engine load. The electronic throttle angle is chosen to maintain the required brake mean effect pressure (BMEP) output. The spark advance (SA) is the crank angle of spark ignition. Maximum brake torque (MBT) point is chosen by adjust the CA50 around 7 9 deg after top dead center (ATDC). For each engine test condition, the mean value of in-cylinder pressure data of 300 consecutive combustion cycles is used to calculate experimental heat release and use these values to compare with simulation results.

\subsubsection{VALIDATION RESULTS AND DISCUSSIONS}

Spark timing is commonly used for combustion phase control. After calibration of model parameters, the simulation results of the combustion model are well matched with experimental data over a wide range of spark timing range. Figure 3.8 and Figure 3.9 show the simulated results of MFB and in-cylinder pressure at three spark timing conditions. These figures demonstrate that the simulated MFB and in-cylinder pressure values fit well with experimental data. 


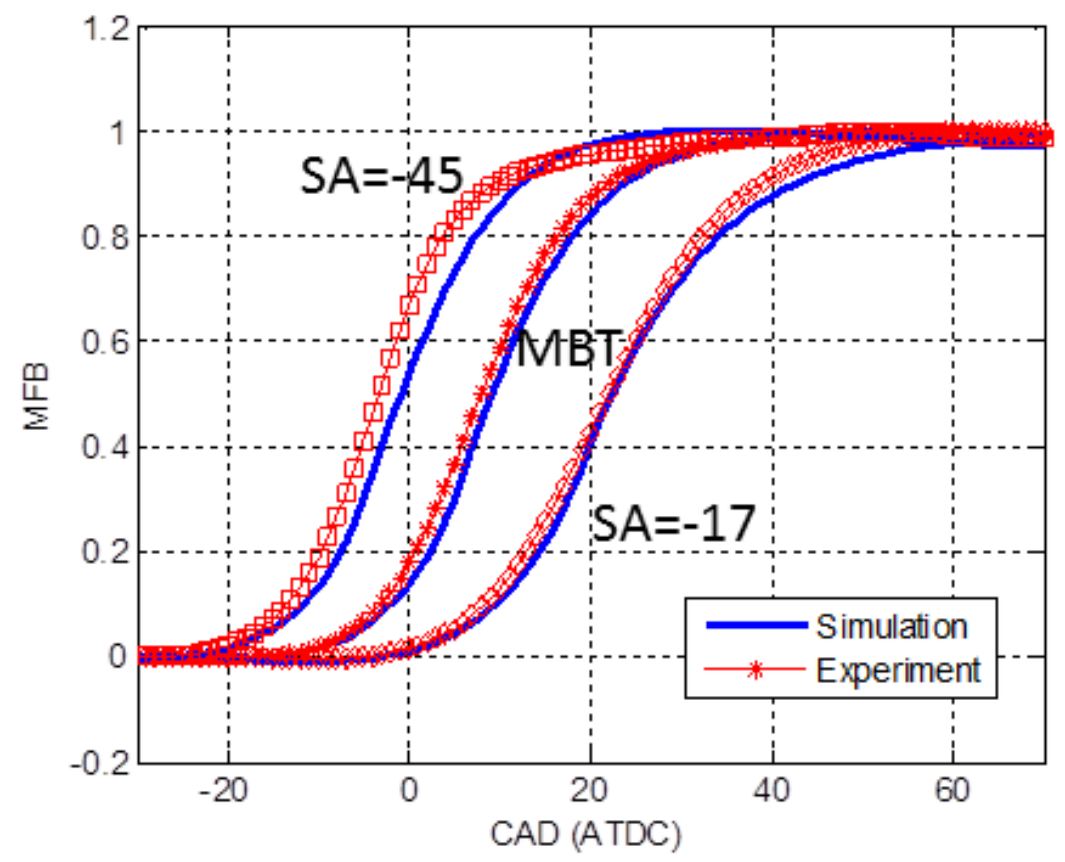

Figure 3.8: Comparison of MFB between predicted results and experimental data under different spark advances, test 1240, 1241 and 1254, $1500 \mathrm{rpm}, 2.62 \mathrm{bar}$.

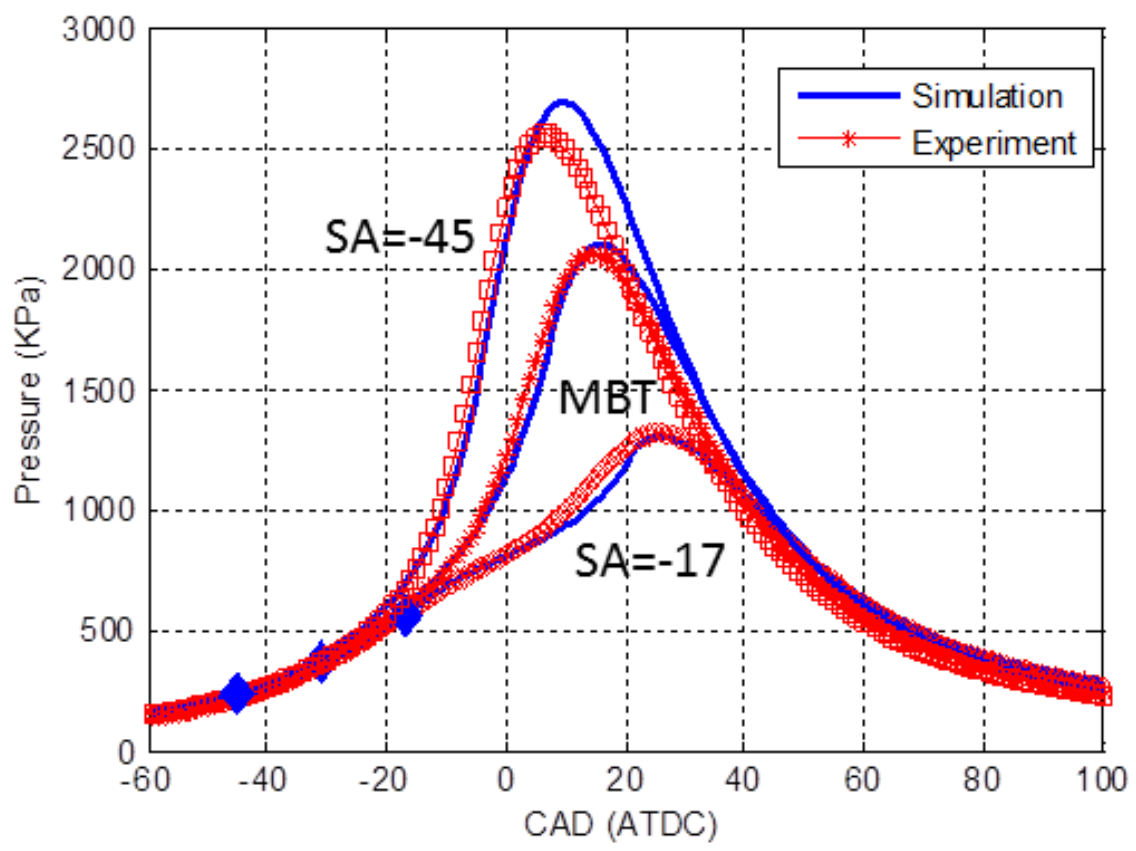

Figure 3.9: Comparison of in-cylinder pressure between predicted results and experimental data under different spark advances, test 1240, 1241 and 1254, $1500 \mathrm{rpm}$, 2.62 bar. 
To validate the performance of the combustion model at lean combustion situation, a set of lambda sweep tests are performed. Table 3.4 lists the parameters gamma and combustion efficiency values used in the simulation. In lambda sweep tests, the lambda value varies from 1 to 1.35 with 0.05 as increment. The engine runs at $2000 \mathrm{rpm}$ and 5 bar BMEP. The heat capacity ratio in expansion process $\left(\gamma_{e}\right)$ is chosen based on the incylinder temperature reduction and the air composition in the mixture. The values of the combustion efficiency $\eta_{c}$ are referred from figure 3-9 of Heywood [12] with the consideration of matching the experimental pressure results. Figure 3.10 and Figure 3.11 show the comparison of simulated MFB and pressure with experimental results. The simulation results match the experimental data properly with the calibrated parameter values.

Table 3.4: Lambda sweep test conditions in simulation

\begin{tabular}{|c|c|c|c|}
\hline TEST & Lambda & $\gamma_{e}$ & $\eta_{c}$ \\
\hline 1640 & 1.0 & 1.26 & 0.85 \\
\hline 1641 & 1.05 & 1.26 & 0.90 \\
\hline 1642 & 1.1 & 1.26 & 0.90 \\
\hline 1643 & 1.15 & 1.27 & 0.92 \\
\hline 1644 & 1.2 & 1.27 & 0.95 \\
\hline 1645 & 1.25 & 1.27 & 0.95 \\
\hline 1646 & 1.3 & 1.28 & 0.95 \\
\hline 1647 & 1.35 & 1.28 & 0.95 \\
\hline
\end{tabular}




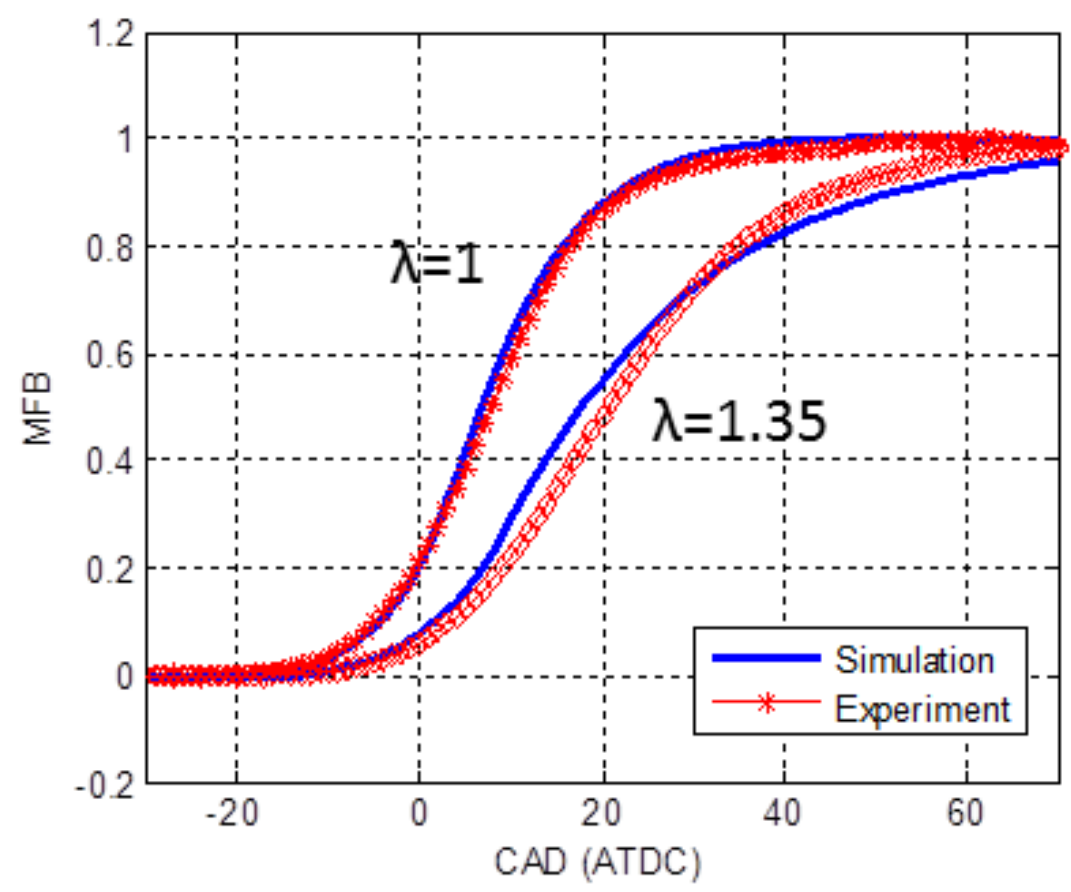

Figure 3.10: Comparison of MFB vs. crank angle with experimental data of test 1640 $($ lambda $=1.0)$ and $1647($ lambda $=1.35)$.

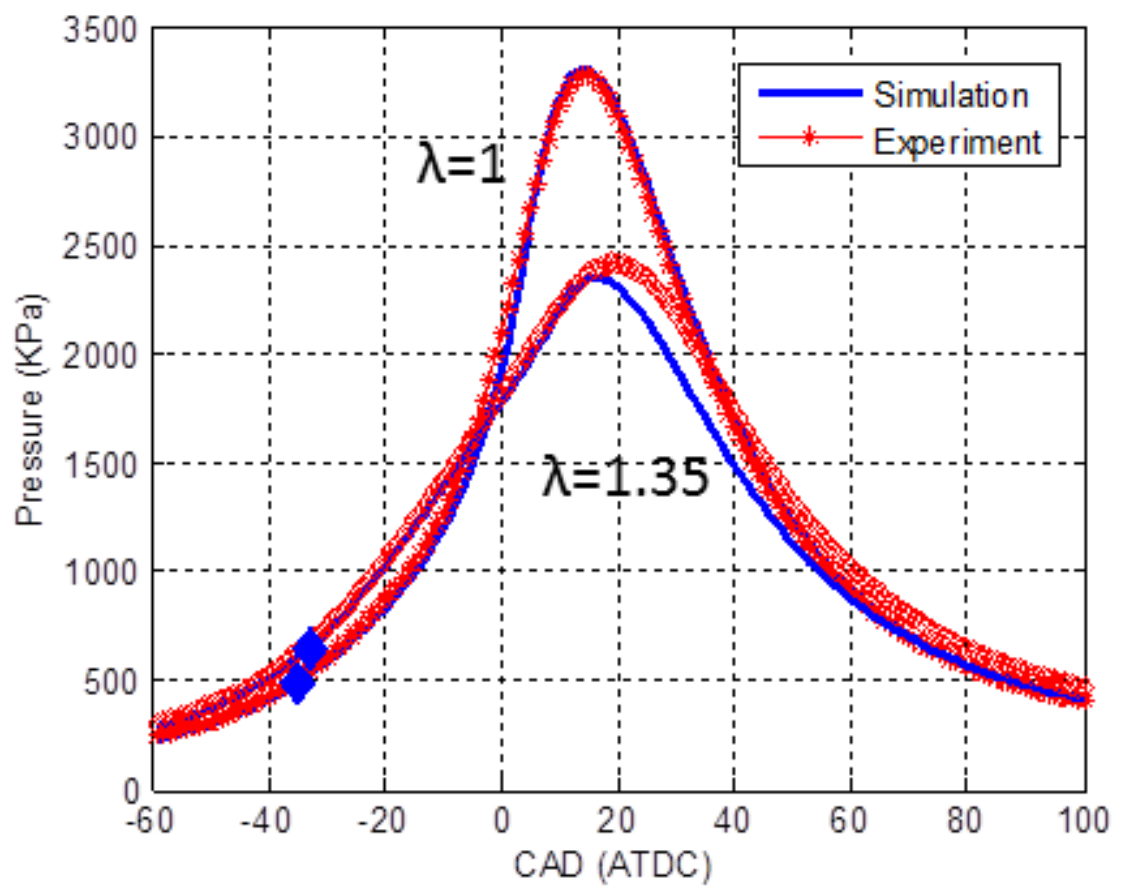

Figure 3.11: Comparison of in-cylinder pressure vs. crank angle with experimental data of test $1640($ lambda $=1.0)$ and $1647($ lambda $=1.35)$. 
Table 3.5 compares crank angle positions after TDC of 10\% MFB (CA10), 50\% MFB (CA50) and 90\% MFB (CA90) between simulation and experimental data. The model resolution is 1 crank angle degree to match the sample rate of the data acquisition system in this case. The precise values of CA 10, CA50 and CA90 are found using interpolation of the MFB data points. Burn duration $0 \sim 10 \%$ is the period from spark ignition to $10 \%$ MFB and it represents the length of early combustion stage. Burn duration 10 90\% is the period from $10 \%$ to $90 \% \mathrm{MFB}$ and it represents the length of main combustion stage. Figure 3.12 to Figure 3.14 show the comparisons of CA50, 0 10\% and 10 90\% burn duration respectively.

Table 3.5: Comparisons of CA10, CA50 and CA90 between experimental data and simulation results

\begin{tabular}{|c||c|c||c|c||c|c||c|c|}
\hline \multicolumn{1}{|c|}{ TEST } & \multirow{2}{*}{ Lambda } & \multicolumn{1}{c||}{ SI } & \multicolumn{2}{c||}{ CA10 } & \multicolumn{2}{c||}{ CA50 } & \multicolumn{2}{c|}{ CA90 } \\
\cline { 3 - 8 } & & (ATDC) & Exp & Sim & Exp & Sim & Exp & Sim \\
\hline \hline 1640 & 1.00 & -35 & -4.9 & -4.3 & 7.8 & 6.8 & 22.7 & 21.6 \\
\hline 1641 & 1.05 & -32 & -2.6 & -2.5 & 10.6 & 9.2 & 26.2 & 26.2 \\
\hline 1642 & 1.10 & -32 & -2.7 & -2.5 & 10.6 & 9.8 & 26.0 & 28.5 \\
\hline 1643 & 1.15 & -32 & -2.6 & -3.0 & 10.8 & 9.5 & 27.5 & 29.9 \\
\hline 1644 & 1.20 & -33 & -2.9 & -3.7 & 11.0 & 9.4 & 27.3 & 32.0 \\
\hline 1645 & 1.25 & -32 & -1.2 & -2.7 & 13.5 & 11.3 & 32.6 & 37.0 \\
\hline 1646 & 1.30 & -29 & 1.2 & -0.8 & 17.3 & 14.1 & 38.0 & 44.3 \\
\hline 1647 & 1.35 & -27 & 3.4 & 1.7 & 20.6 & 17.8 & 44.9 & 52.0 \\
\hline
\end{tabular}




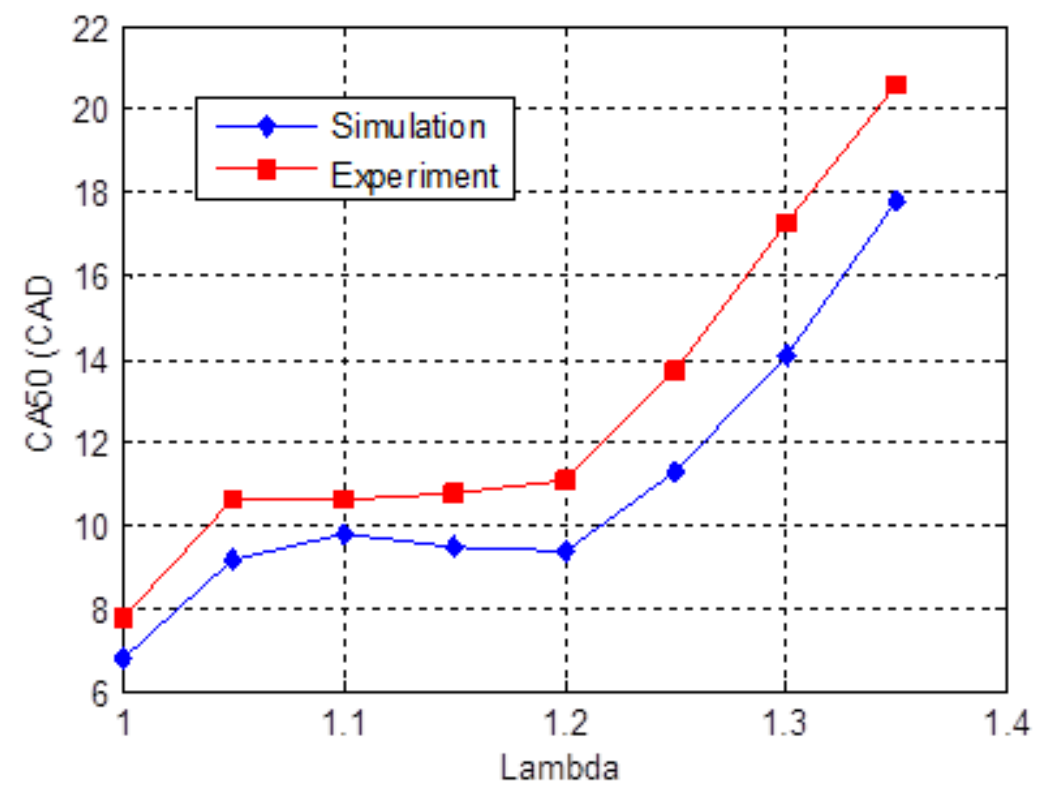

Figure 3.12: Comparison of CA50 values between simulation results and experimental data, tests 1640 to 1647 (lambda sweep).

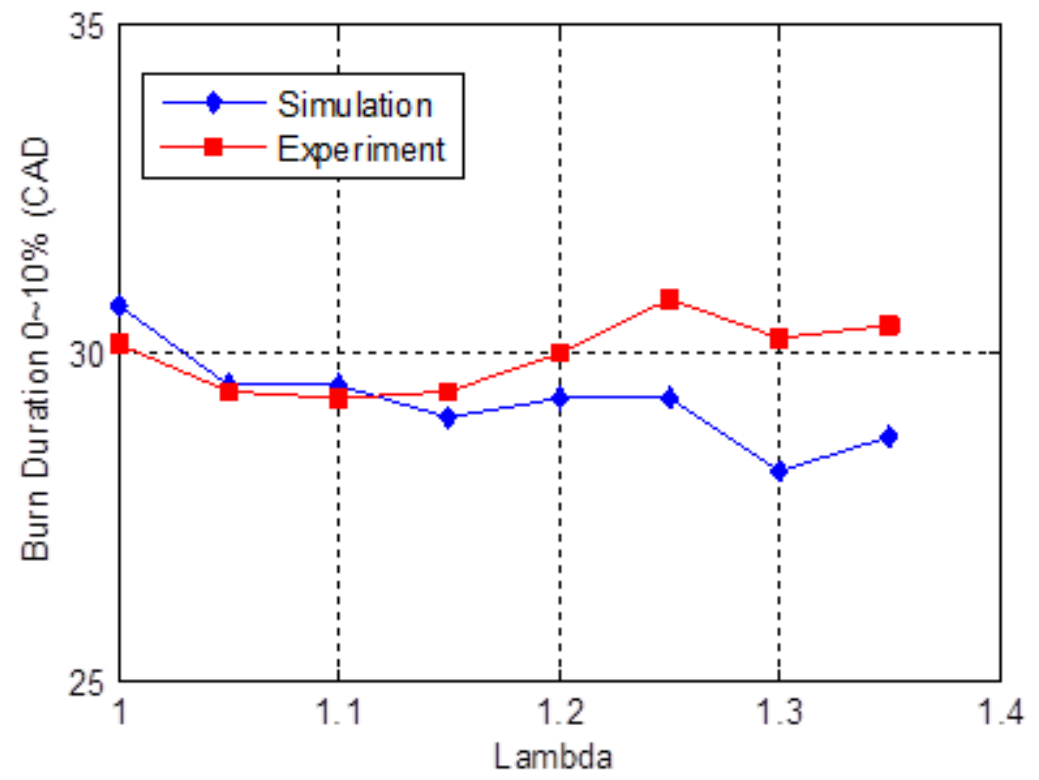

Figure 3.13: Comparison of $0 \sim 10 \%$ burn duration values between simulation results and experimental data, tests 1640 to 1647 (lambda sweep). 


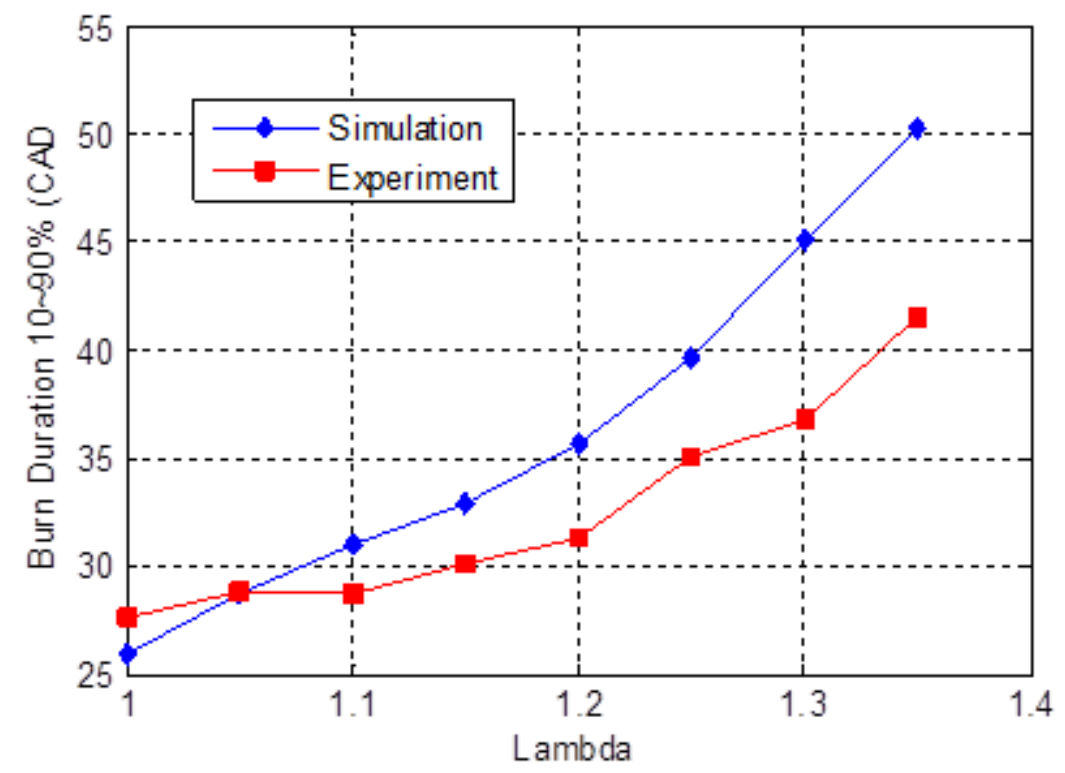

Figure 3.14: Comparison of 10 90\% burn duration values between simulation results and experimental data, tests 1640 to 1647 (lambda sweep).

From the comparisons in the table and figures, some conclusions could be made. Overall, the simulation results of burn durations represent proper trend comparing with experimental observations. The prediction of combustion model has better agreement with experimental data when lambda is around 1 since parameters are tuned with stoichiometric condition. The deviation increases while combustion becomes leaner. The estimation errors for $0 \sim 10 \%$ burn durations are less than that of $10 \sim 90 \%$ burn duration. 


\section{STUDY CYCLIC VARIATION USING DEVELOPED COMBUSTION MODEL}

As discussed in literature review, cycle-to-cycle variation exists in the combustion of IC engines. The variation may be caused by several reasons. Except the variation of engine operation conditions, some other variation sources in the combustion may exist. In this chapter, the original variation sources are introduced in to complete the combustion model and their influence is validated through the comparison of cyclic variation between simulation results and that exists in experimental results.

\subsection{CYCLICVARIATION IN ENGINE COMBUSTION}

To analyze combustion variability, the test conditions, including intake manifold pressure, temperature, spark, valve timing and fuel delivering amount are fixed in the engine tests. The data starts to be recorded when the intake manifold and engine coolant temperatures are stable. The electronic throttle position is fixed to maintain intake pressure. The fuel injectors are controlled to deliver fuel with the amount based on the intake air mass. Although all the test inputs are controlled with small amount of variations, the variation of the observed in-cylinder pressure curves is substantial.

Figure 4.1 gives the time-based intake manifold pressures of 600 successive combustion cycles captured by ACAP system. The pressure values have relative high fluctuation with a mean value around $62.5 \mathrm{KPa}$. Figure 4.2 and Figure 4.3 show the cyclic variation of intake pressure and MFB for the cylinder \#1 in test 1640 (2000 rpm, 5 bar BMEP, lambda $=1$, MBT). Figure 4.4 and Figure 4.5 show the cyclic variation of intake pressure and MFB in test 1647 (2000 rpm, 5 bar BMEP, lambda =1.35). Comparing with these figures, we can see that the cyclic variation is enlarged when engine runs leaner (lambda $=1.35)$. 




Figure 4.1: Intake manifold pressure measured by ACAP system, test 1640, 600 cycles, $2000 \mathrm{rpm}, 5$ bar BMEP, lambda = 1, MBT.

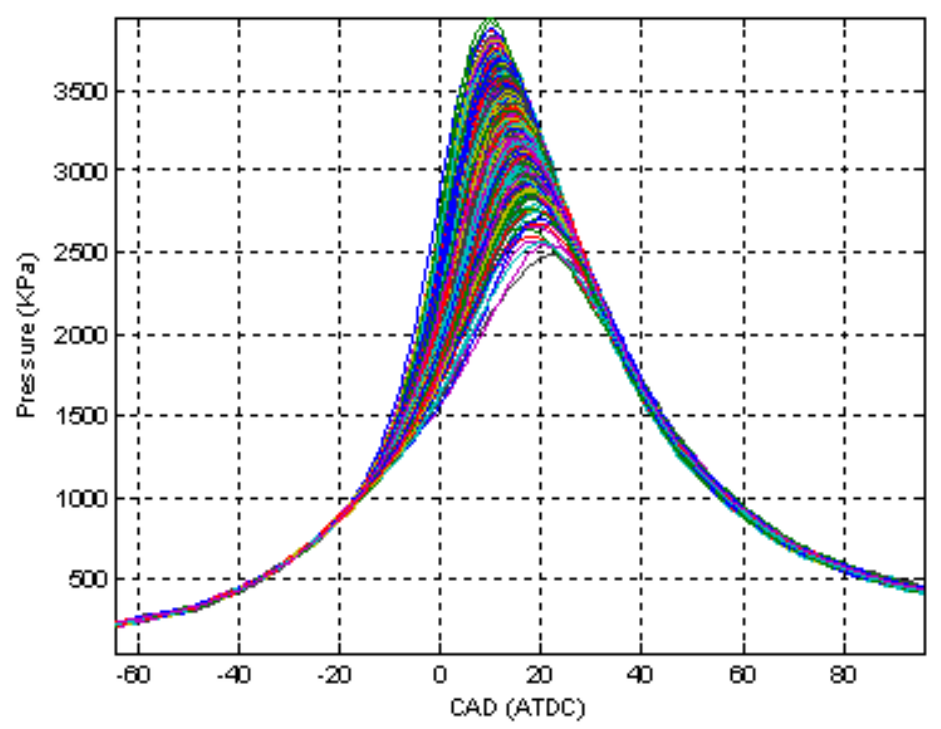

Figure 4.2: Cyclic variation in measured pressure vs. crank angle curves of 600 cycles, test 1640, $2000 \mathrm{rpm}, 5$ bar BMEP, lambda =1, MBT. 


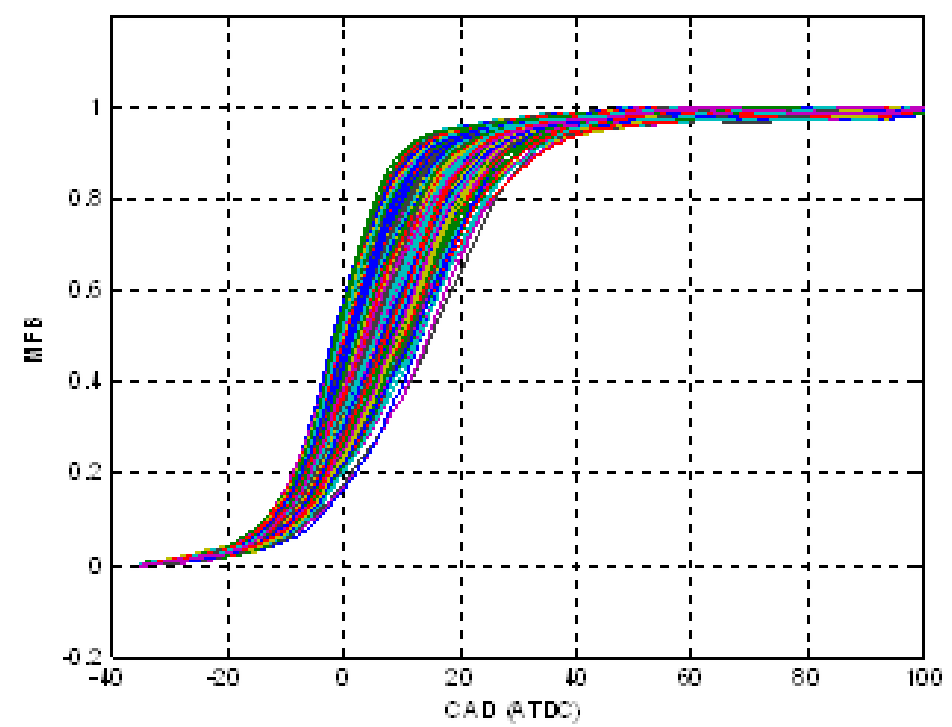

Figure 4.3: Cyclic variation in MFB vs. crank angle curves, test 1640, 600 cycles, 2000 rpm, 5 bar BMEP, lambda = 1, MBT.



Figure 4.4: Cyclic variation in measured pressure vs. crank angle curves of 600 cycles, test 1647, $2000 \mathrm{rpm}, 5$ bar BMEP, lambda $=1.35$. 


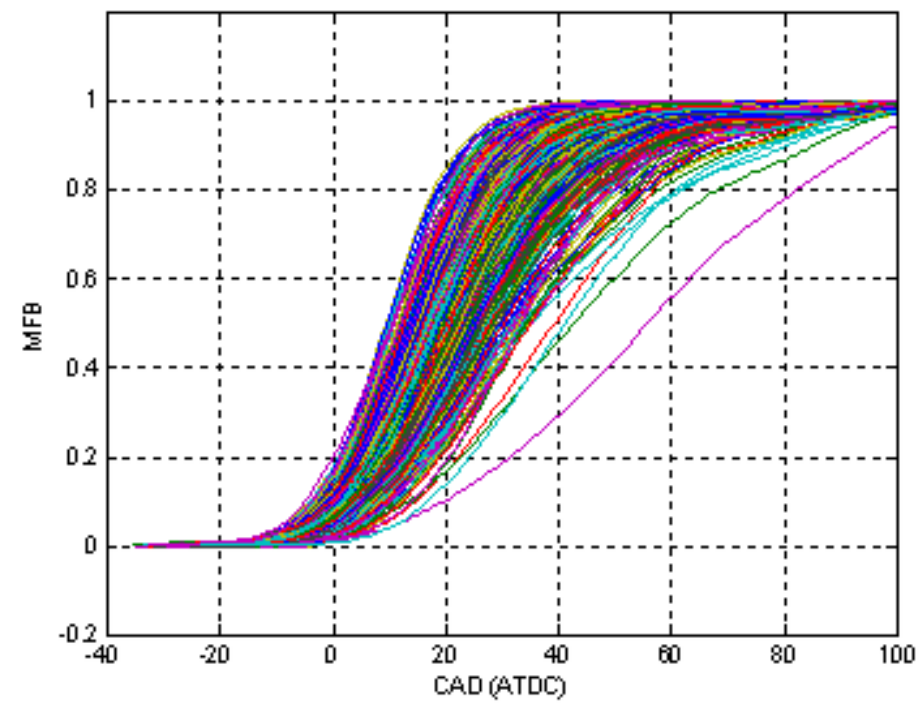

Figure 4.5: Cyclic variation in MFB calculated by measured data vs. crank angle curves of 600 cycles, test 1647, $2000 \mathrm{rpm}, 5$ bar BMEP, lambda $=1.35$.

The cyclic variations are reflected in in-cylinder pressure and can be indicated by COV of IMEP which is calculated by equation (33) [12]. Indicated mean effect pressure values illustrate the effective work from the combustion of each cycle. It is the work produced in each cycle divided by the clearance volume as shown in equation (34). The COV of IMEP values of engine tests at different lean combustion levels are shown in Figure 4.6.

$$
\begin{gathered}
C O V(I M E P)=\frac{\operatorname{std}(\operatorname{IMEP})}{\operatorname{avg}(I M E P)} \times 100 \% \\
I M E P=\frac{\int p d V}{V_{d}}
\end{gathered}
$$




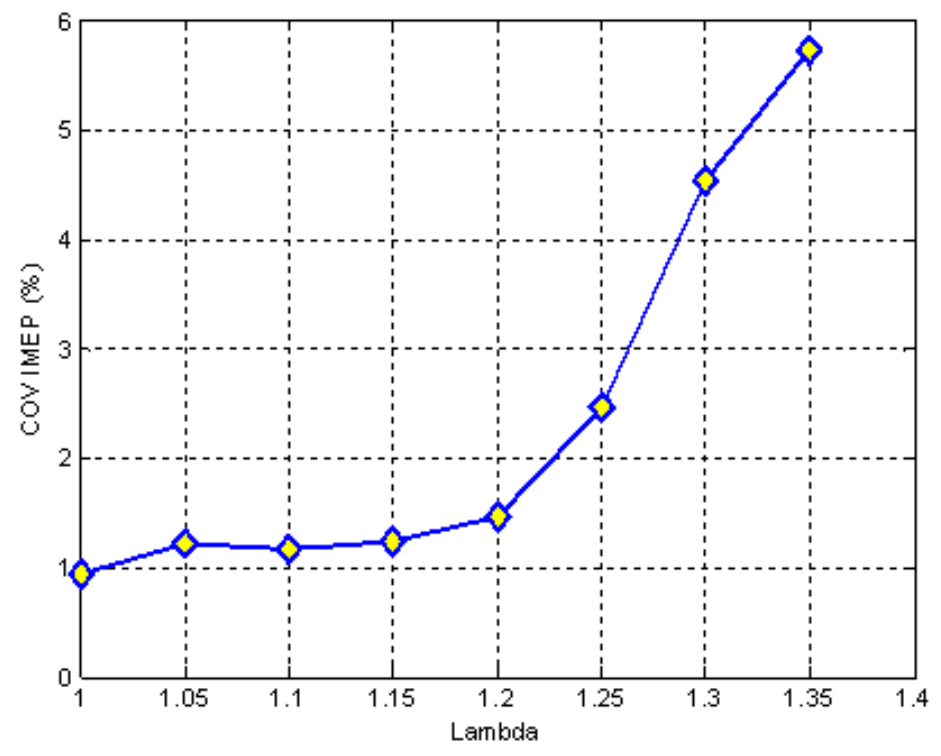

Figure 4.6: COV of IMEP vs. lambda from test results, test 1640 to 1647, average of 600 cycles, $2000 \mathrm{rpm}, 5$ bar BMEP, 0\% EGR.

Figure 4.6 illustrates a very common phenomenon that the COV of IMEP keeps low near lambda $=1$ but increase rapidly when passing a certain lean point. From the combustion burning process, the MFB curves in Figure 4.3 and Figure 4.5 show that the variation of mass fraction burned appears from the start of combustion. The variation keeps increasing during the progress of combustion. The analysis results in Ayala [1] reveal that the periods from ignition to burning $10 \%$ of the mass (10\% burn duration) obey a normal distribution as shown in Figure 4.7 (a) and (b). The normal distribution demonstrates the initial combustion variation nature. As the combustion continues, the variation of burning duration becomes larger in amount and also gradually losses the symmetry. It is more obvious in the case of high lean condition. For the advanced combustion cycles, their deviations from average cycle are not large. However, for the retarded ones, their deviations in early stage could lead worse and worse situation for fuel burning in the rest of combustion period. In severe cases like the MFB curves in Figure 4.5, the partial mass burning of some of the cycles may occur which will lead inefficient use of fuel. 




(a)

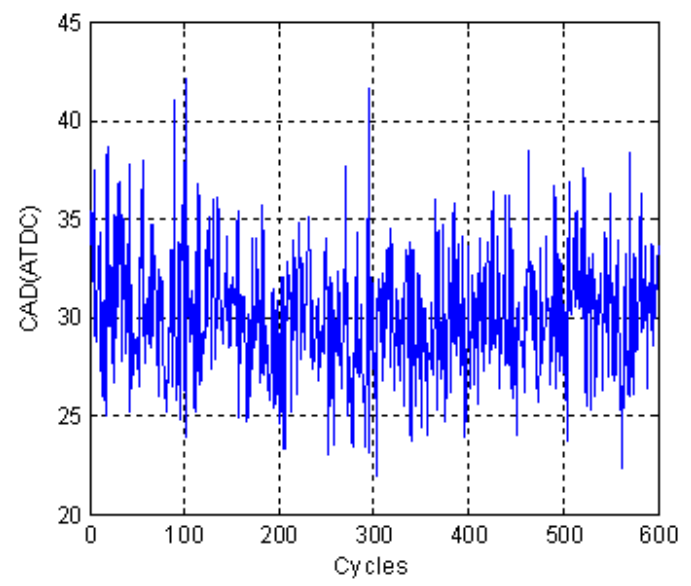

(c)

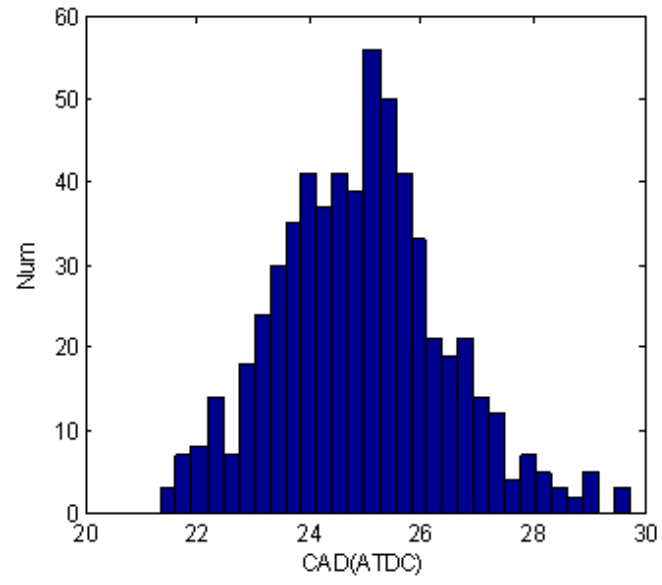

(b)

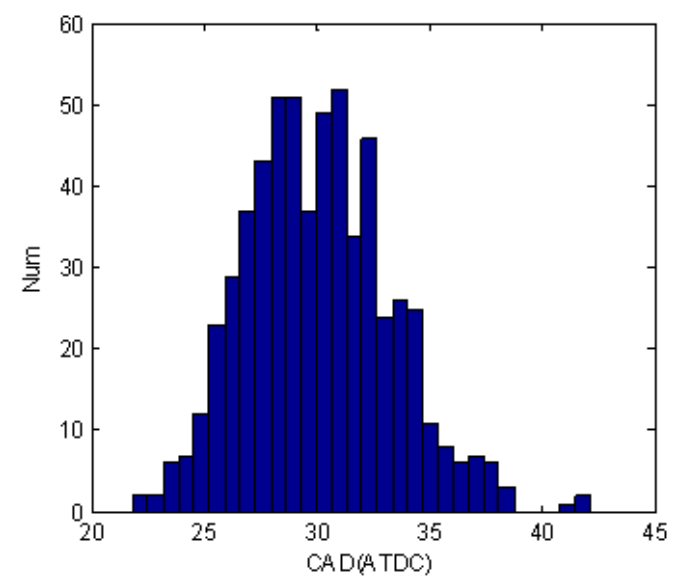

(d)

Figure 4.7: (a) $0 \sim 10 \%$ burn duration (b) $0 \sim 10 \%$ burn duration distribution, (c) $10 \sim 90 \%$ burn duration (d) 10 90\% burn duration distribution, test 1640, 600 cycles, $2000 \mathrm{rpm}, 5$ bar BMEP, lambda $=1$.

In stoichiometric condition, the variation of MFB curves is relative small, and the deviation increases slowly as combustion continues. For the lean operation as shown in Figure 4.8 , the variation s for both $0 \sim 10 \%$ and $10 \sim 90 \%$ burn duration are increased. The distribution of 10 90\% burn duration shows obvious asymmetry. 




(a)



(c)



(b)

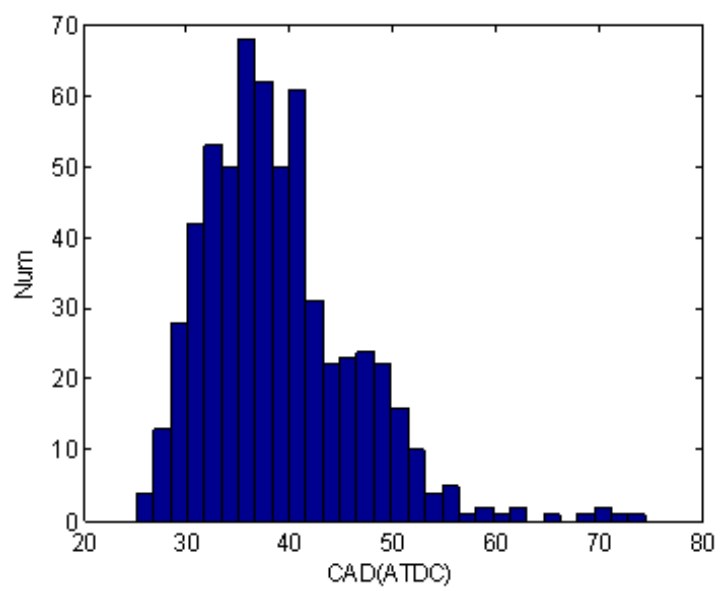

(d)

Figure 4.8: (a) $0 \sim 10 \%$ burn duration (b) $0 \sim 10 \%$ burn duration distribution, (c) 10 90\% burn duration (d) 10 90\% burn duration distribution, test 1647, 600 cycles, $2000 \mathrm{rpm}, 5$ bar BMEP, lambda $=1.35$.

\subsection{CYCLIC VARIATION IN COMBUSTION SIMULATION}

With cyclic variation observed in engine test results, some fluctuation sources could be introduced into the combustion model in order to generate simulation results with similar 
variations pattern. The simulation results are compared with lambda sweep engine test data 1640 to 1647.

In the experiment test engine inputs are maintained to be constant, most of them have little fluctuation or are insensitive to the in-cylinder pressure values. The fluctuations are introduced by adding a normal noise source with individual input sources in the SIMULINK model. The major fluctuation input is the intake pressure values. For test 1640 stoichiometric condition the variation of intake manifold pressure is measured and shown in Figure 4.1. The presumed fluctuation sources and their variance are listed in Table 4.1. The simulated pressure curves introduced with only these fluctuation sources is shown in Figure 4.9. Figure 4.9 (a) is the peak in-cylinder pressure (PP) of each cycle versus its location (PPL). The PP vs. PPL scatter plot describes the variation of incylinder pressure values.

The variation in pressure curves of successive cycles is simulated with the introduced fluctuations. However comparing with the variation of experimental results the variation is not large enough, even under the stoichiometric condition where cyclic variation is small. From PP vs. PPL scatter, it is found that with the introduced variation the model succeeds to simulate enough deviation in the peak pressure values. However, it fails to simulate the variation in combustion phase aspect. In lean combustion condition, the variations of these introduced inputs are not changed much but from the experimental results there is much more variation in both peak pressure values and phases.

Table 4.1: Amount of introduced variation sources of engine inputs and parameters

\begin{tabular}{|l|c|}
\hline Variation Item (reference value) & Variance \\
\hline Intake manifold pressure (60) & 0.5 \\
\hline Actual AFR (1.0) & $1 \mathrm{e}-5$ \\
\hline Gamma (1.3) & $1 \mathrm{e}-5$ \\
\hline Residual gas fraction (0.15) & $1 \mathrm{e}-2$ \\
\hline Combustion efficiency $(0.85)$ & $1 \mathrm{e}-5$ \\
\hline
\end{tabular}




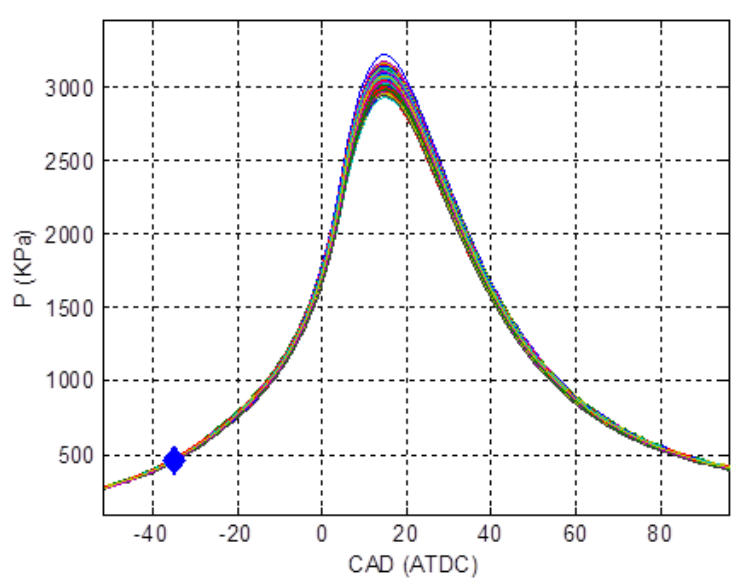

(a)

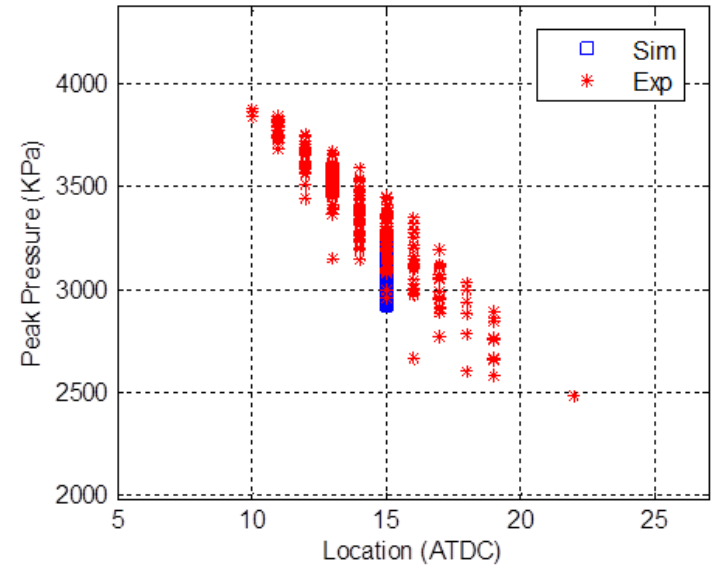

(b)

Figure 4.9: (a) Simulated pressure vs. crank angle curves (b) PP vs. PPL scatter, introduced with input fluctuations only, test 1640, 300 cycles, 2000 rpm, 5 bar BMEP, lambda $=1$.

To better match experimental data, additional fluctuation sources need to be considered. Aghdam et al. [16] introduce fluctuation in turbulence into the fundamental combustion model. The peak pressure vs. peak pressure location scatter matches that of experimental result but the peak pressure points have too regular linear positions. In reality turbulent flow has the variation nature. The turbulent flow structure is influenced by parameters such as piston speed, mass density, pressure and temperature, so the turbulent level is indirectly affected by lean combustion level. To further simulate the combustion variation, the initial variations in the fuel burning speed and the early flame development need to be considered.

From the expressions of fundamental combustion model described previously, the laminar burning speed $\left(S_{L}\right)$ and the eddy burning time $\left(\tau_{b}\right)$, these parameters are related to the fuel burning rate. The exponential factor with time constant $\left(\tau_{b} / n_{\tau}\right)$ related to eddy burning time is used to express the growth of the early flame. In SIMULINK model the introduction of variation is by adding normal noise sources to the calculations of eddy 
burning time $\tau_{b}$ and the parameter $1 / n_{\tau}$ in the time constant. An assumed correlation value is set for these two random factors.

Based on the research [15] there is correlation between the duration of early flame formation and burning rate. The combustion cycle with longer early flame development period should have more probability with longer eddy burning time. The generation of two correlated random values can be achieved through equation (35). rand $_{1}$ and rand ${ }_{2}$ are two independent random vectors.

$$
\begin{aligned}
& x_{1}=\text { rand }_{1} \\
& x_{2}=P_{\text {corr }} \cdot \text { rand }_{1}+\sqrt{1-P_{\text {corr }}^{2}} \cdot \text { rand }_{2}
\end{aligned}
$$

Table 4.2: Additional variation sources and their amount introduced into the combustion model

\begin{tabular}{|l|c|}
\hline Variation Items & Variance \\
\hline Turbulent flow $\left(u^{\prime}\right)$ & $1 \mathrm{e}-3$ \\
\hline Eddy burning time $\left(\tau_{b}\right)$ & $5 \mathrm{e}-3$ \\
\hline Flame development factor $\left(n_{\tau}\right)$ & $1 \mathrm{e}-3$ \\
\hline Correlation & 0.6 \\
\hline
\end{tabular}

Table 4.2 lists the additional variation sources that are introduced in the simulation of test 1640 (lambda $=1$ ). Figure 4.10 the PP vs. PPL scatter shows well matching of the simulation results. With the consideration of variation source of eddy burning time, the simulated variation of peak pressure point exists in the combustion phase aspect. To further validate the effort of this method, the simulations under lean combustion conditions are tested. The variances of the introduced values vary. They are adjusted to make matching pp vs. ppl scatters comparing with experimental results. The calibrated parameters are listed in Table 4.3. 


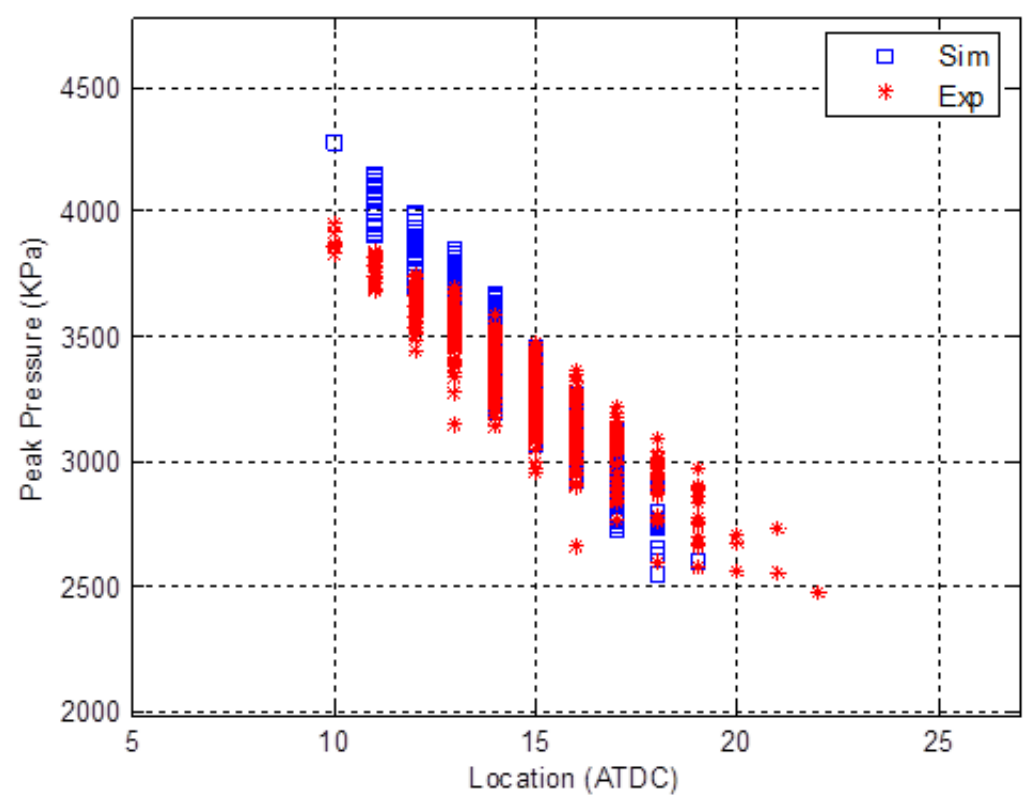

Figure 4.10: PP vs. PPL scatters of simulation and experimental results, introduced with all fluctuation sources listed in Table 4.1 and Table 4.2 in simulation, test 1640, 600 cycles, lambda $=1$.

Table 4.3: Variances of introduced variation sources under different lean conditions

\begin{tabular}{|c|c|c|c|c|}
\hline Test & 1640 & 1642 & 1645 & 1647 \\
\hline Lambda & 1.0 & 1.1 & 1.25 & 1.35 \\
\hline Eddy burning time $\left(\tau_{b}\right)$ & $3 \mathrm{e}-3$ & $5 \mathrm{e}-3$ & $8 \mathrm{e}-3$ & $1.5 \mathrm{e}-2$ \\
\hline Flame development $\left(n_{\tau}\right)$ & $4 \mathrm{e}-3$ & $4 \mathrm{e}-3$ & $5 \mathrm{e}-3$ & $5 \mathrm{e}-3$ \\
\hline
\end{tabular}

The simulation results of PP vs. PPL scatters in different lean combustion level are shown in Figure 4.11 to Figure 4.13. Overall, the simulated variations in pressure match well with those of experimental data except DC shift. The variances are calibrated by comparing the variation in MFB curves with that of experimental results. From the calibrated variance values, it is observed that the variance of eddy burning time $\left(\tau_{b}\right)$ needs to be increased significantly as the lean level increases to make the simulation result match. It can be concluded that the burning time in lean combustion condition is 
not only large in average value but also has large variation which may be the major impact factor of combustion stability.

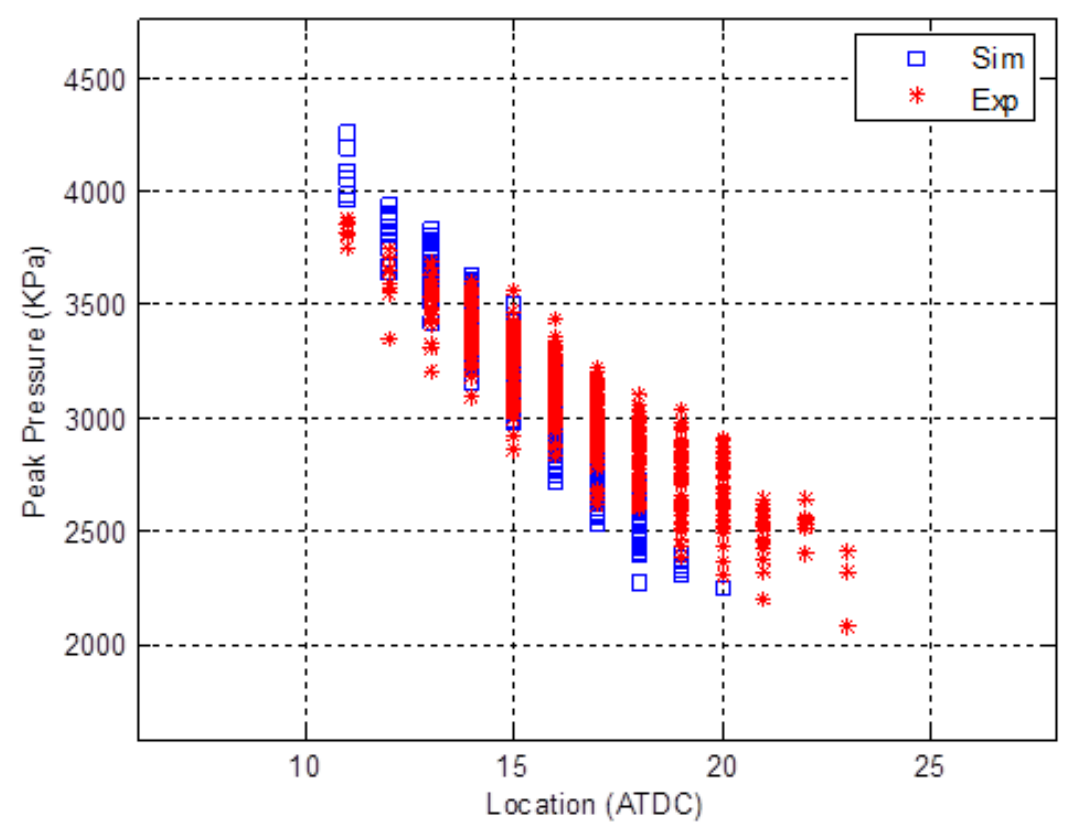

Figure 4.11: PP vs. PPL scatters of simulation and experimental results, introduced with all fluctuation sources in simulation, test 1642, 600 cycles, lambda $=1.1$. 


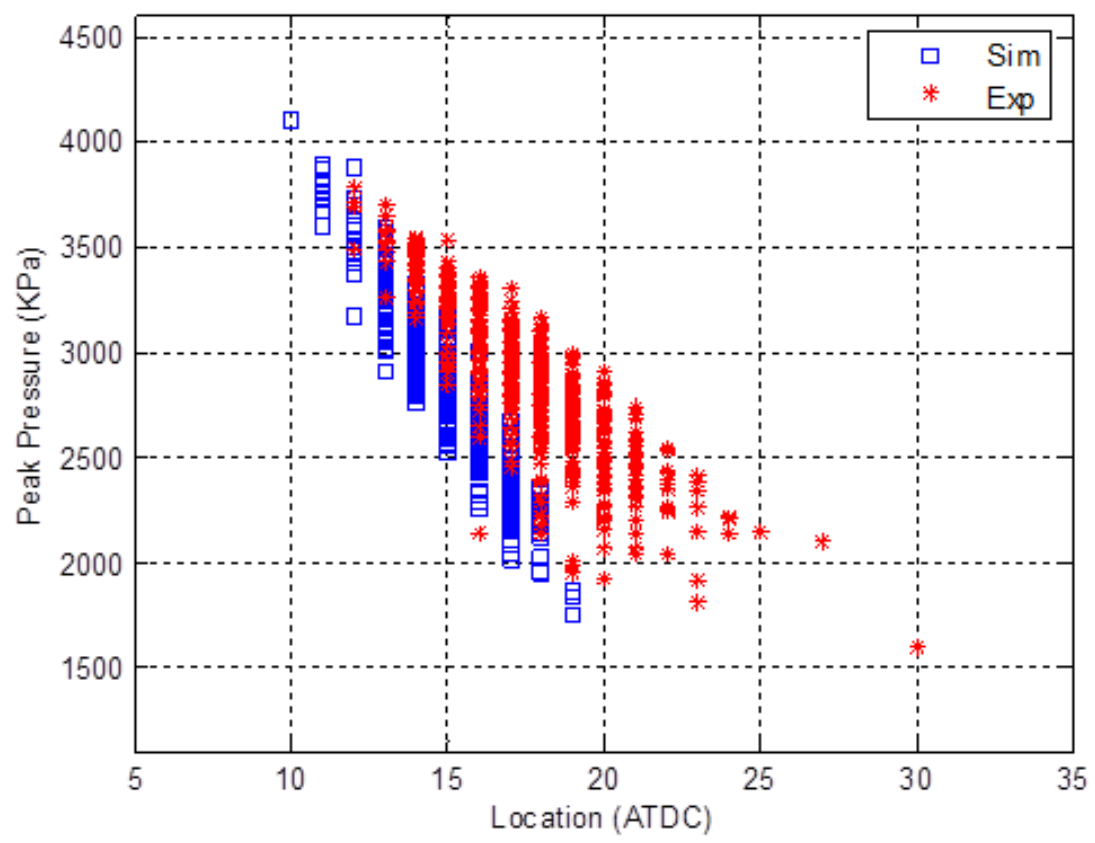

Figure 4.12: PP vs. PPL scatters of simulation and experimental results, introduced with all fluctuation sources in simulation, test 1645,600 cycles, lambda $=1.25$.

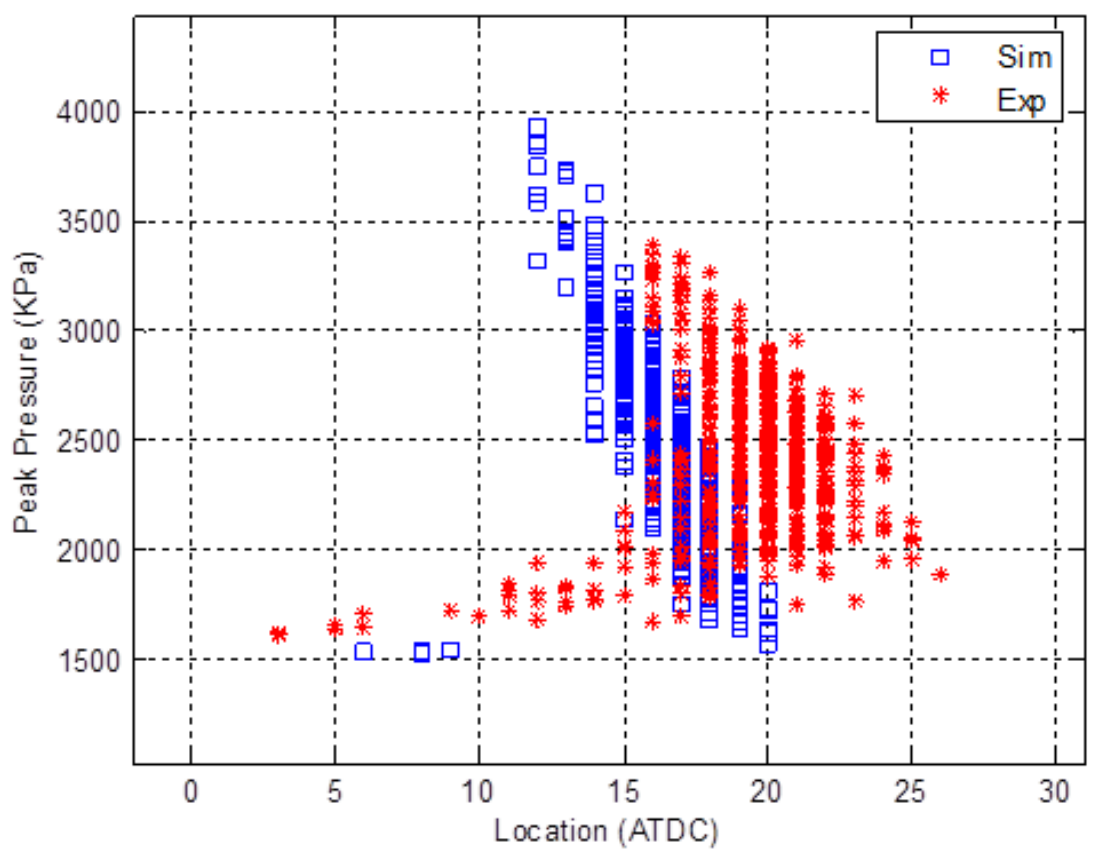

Figure 4.13: PP vs. PPL scatters of simulation and experimental results, introduced with all fluctuation sources in simulation, test 1647,600 cycles, lambda $=1.35$. 
The $0 \sim 10 \%$ and $10 \sim 90 \%$ burn durations of simulation results and experimental data are also compared. For stoichiometric case the simulated and experimental MFB curves of 600 cycles are shown in Figure 4.14. For the lean condition, the MFB curves of 600 cycles under the highest lean condition that in comparison are shown in Figure 4.15. The cyclic variation in simulated MFB results is calibrated to imitate that of experimental MFB curves by adjusting the variances added on flame development rate $\left(n_{\tau}\right)$ and eddy burning time $\left(\tau_{b}\right)$ shown in Table 4.3. The early MFB distribution range is affected by both variations of $n_{\tau}$ and $\tau_{b}$. The main MFB distribution range is affected by the variation of $\tau_{b}$. From the MFB history curves the simulated variation in MFB is similar to experimental ones. The detail distribution can be reflected by the comparison of burn duration distribution. The comparisons of burn duration distribution of stoichiometric and severe lean cases are shown in Figure 4.16 and Figure 4.17 separately.

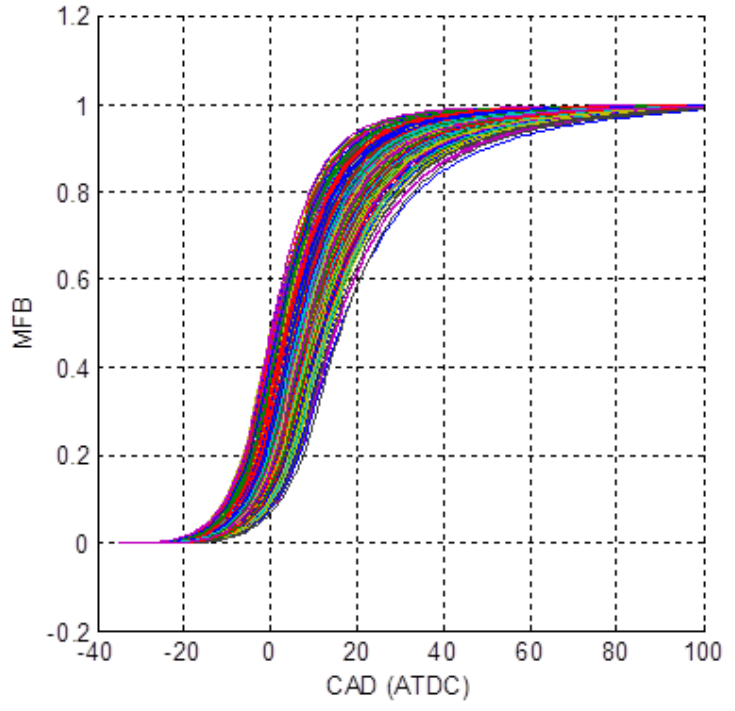

(a)

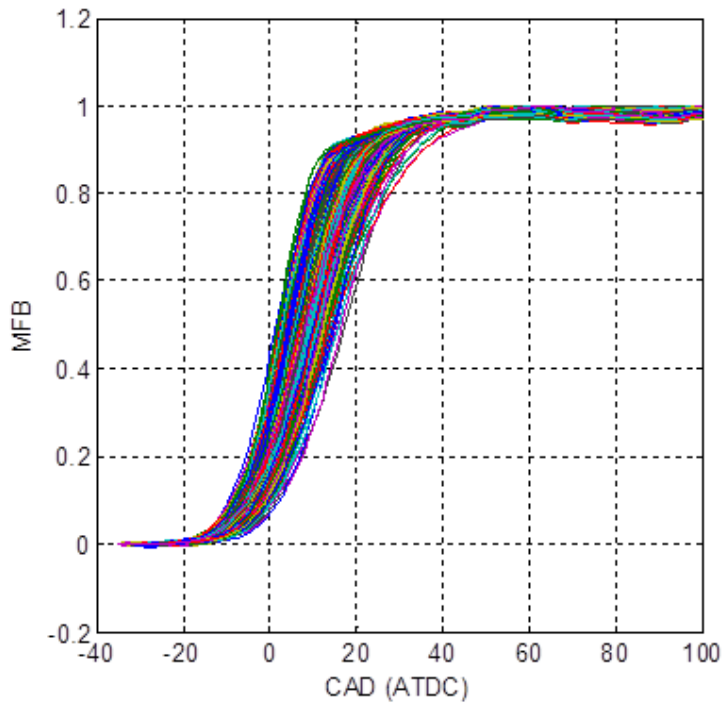

(b)

Figure 4.14: (a) MFB curves of simulation results (b) MFB curves of experimental data, 600 cycles, $2000 \mathrm{rpm}, 5 \mathrm{bar}$, lambda $=1.0$. 


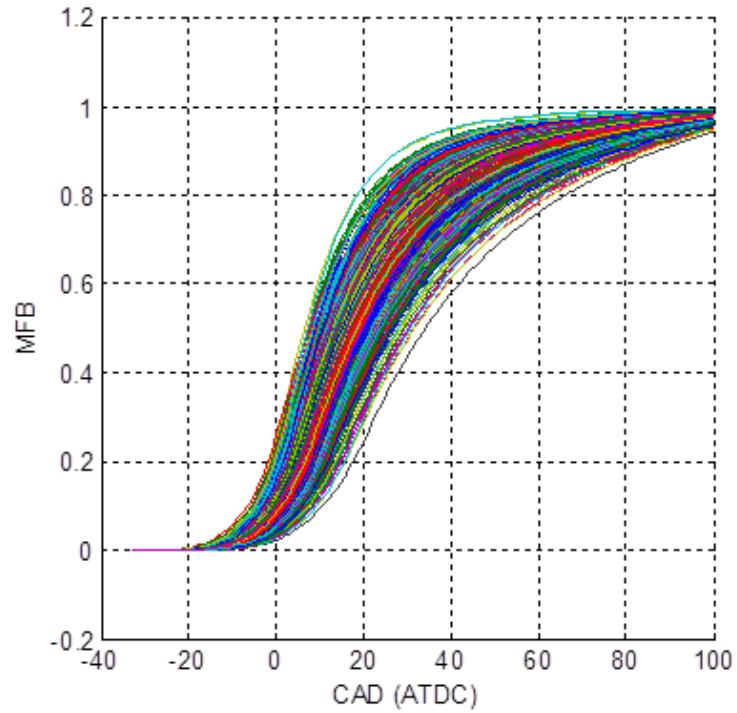

(a)

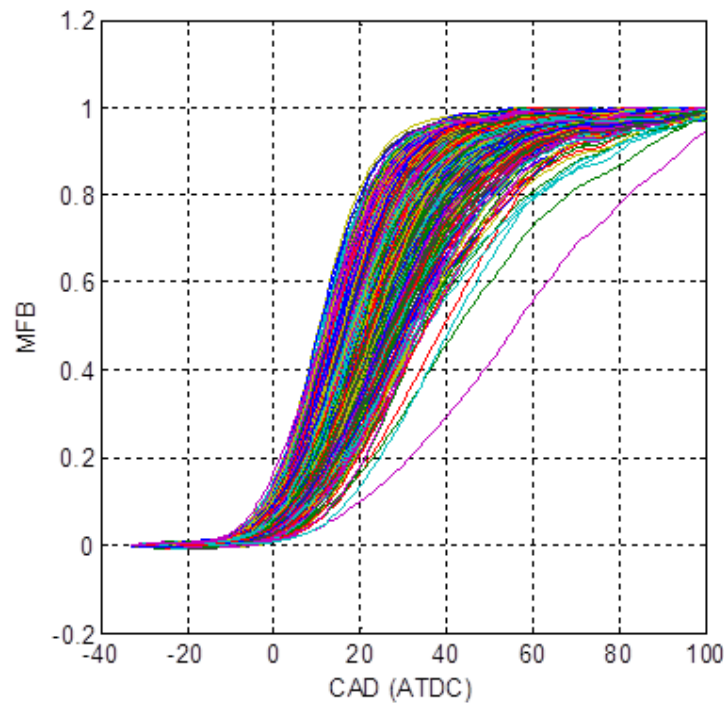

(b)

Figure 4.15: (a) MFB curves of simulation results (b) MFB curves of experimental data, 600 cycles, $2000 \mathrm{rpm}, 5$ bar, lambda $=1.35$. 


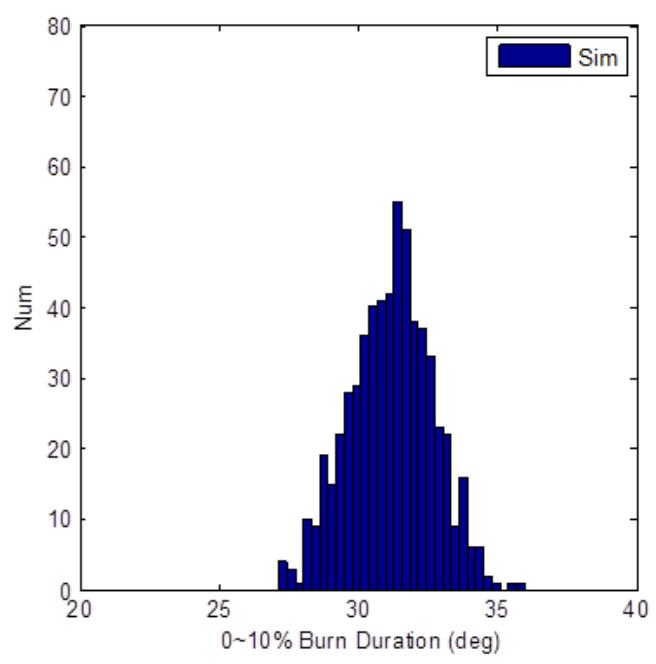

(a)

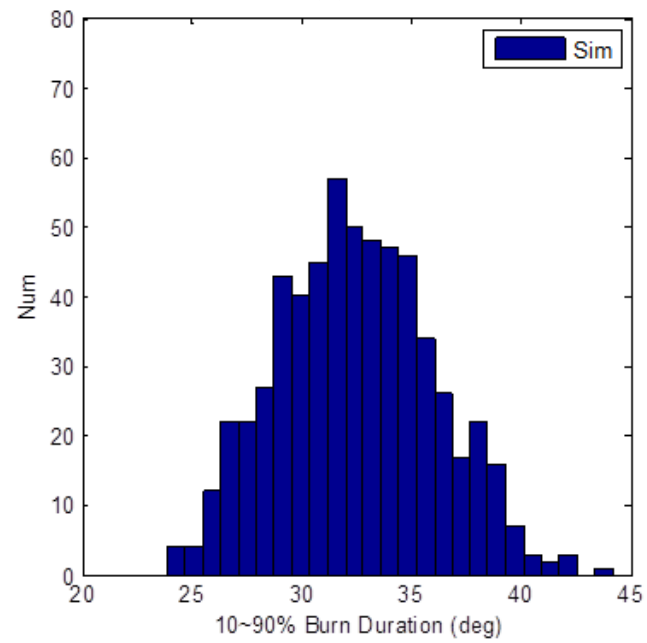

(c)

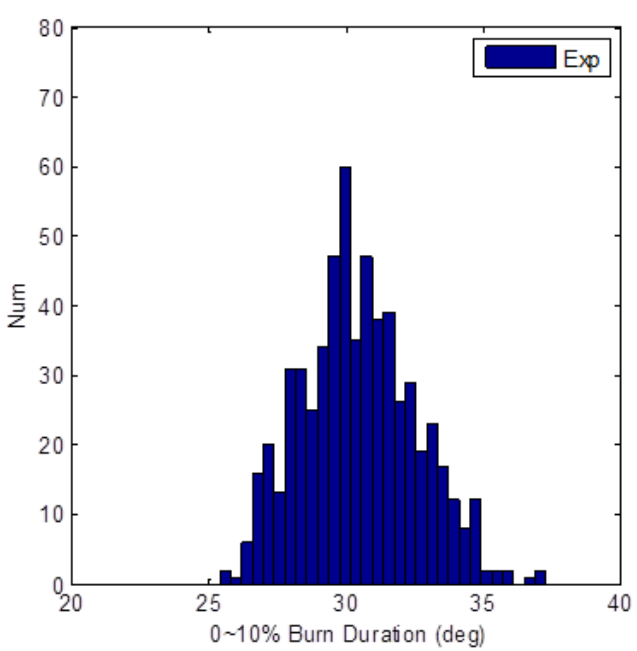

(b)

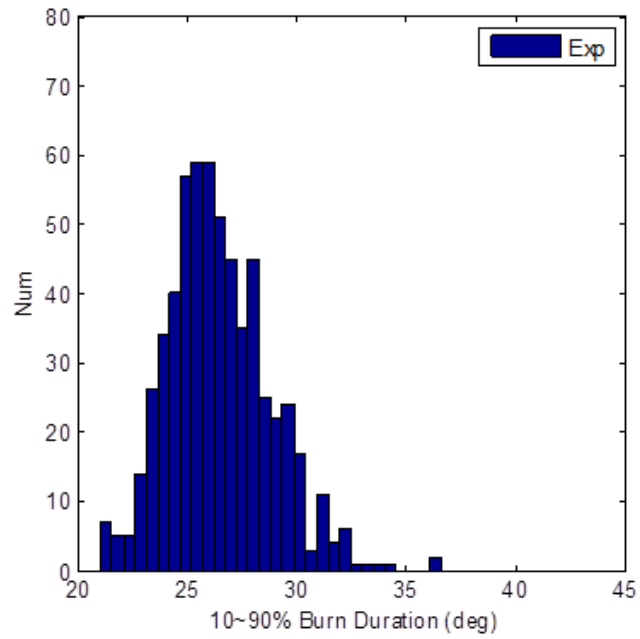

(d)

Figure 4.16: (a) Distribution of 0 10\% burn duration of simulation results (b) distribution of $0 \sim 10 \%$ burn duration of experimental data (c) distribution of 10 90 burn duration of simulation results (d) distribution of 10 90\% burn duration of experimental data, 600 cycles, $2000 \mathrm{rpm}, 5$ bar, lambda $=1.0$. 


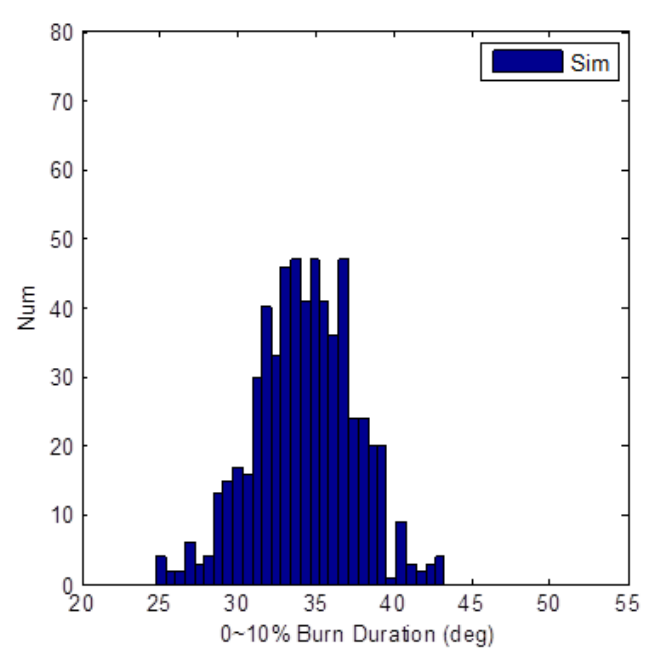

(a)

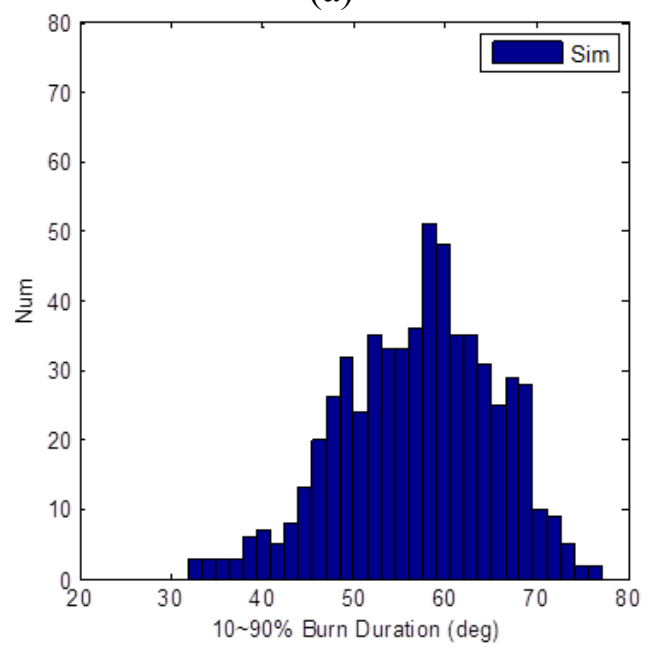

(c)

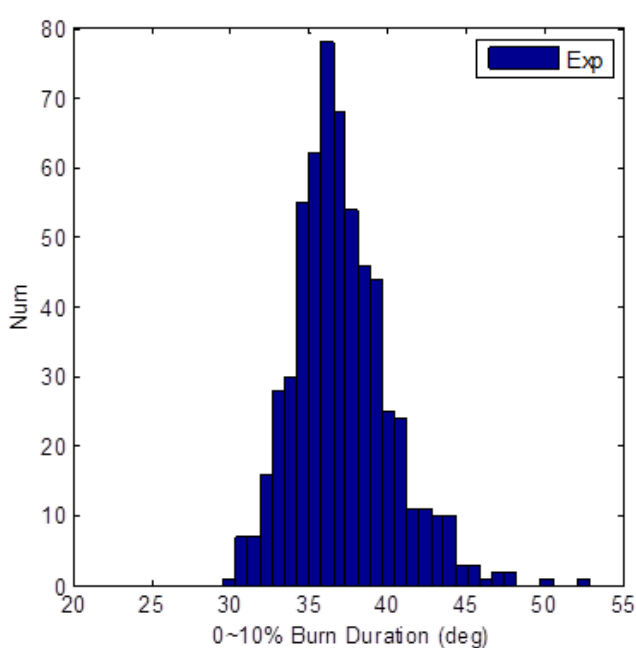

(b)

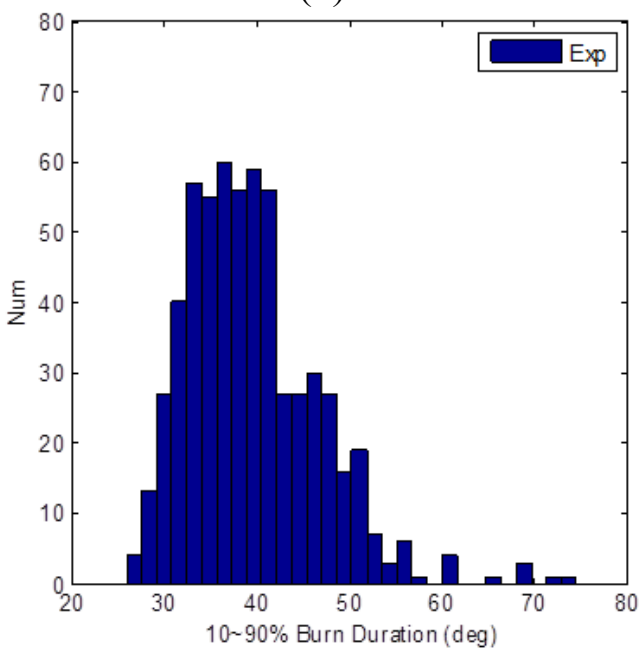

(d)

Figure 4.17: (a) Distribution of $0 \sim 10 \%$ burn duration of simulation results (b) distribution of $0 \sim 10 \%$ burn duration of experimental data (c) distribution of 10 90 burn duration of simulation results (d) distribution of 10 90\% burn duration of experimental data, 600 cycles, $2000 \mathrm{rpm}, 5$ bar, lambda $=1.35$.

In stoichiometric case, the distribution of simulated MFB has high similarity with experimental data in early stage $(0 \sim 10 \%$ burn duration in Figure 4.16 (a) and (b)). However, the 10 90\% burn duration distribution from simulation has larger average value and range than that of experimental data shown in Figure 4.16 (c) and (d). That may be caused by the simulation error in the end part of MFB curves during combustion. In lean condition, the $0 \sim 10 \%$ burn duration is not as concentrated as the experimental distribution shown in Figure 4.17 (a) and (b). The range of 10 90\% burn duration 
distribution is approximately similar to the experimental one shown in Figure 4.17 (c) and (d). However, the asymmetry of the long burn duration direction in the experimental $10 \sim 90 \%$ distribution is not successfully simulated.

Another important indicator of combustion stability is the COV of IMEP. Table 4.4 lists all the COV of IMEP calculated from the simulated pressures and experimental pressure data with the fluctuation parameters with values discussed above. The COV of IMEP values of the simulation with the introduced variation sources are all higher than that of experimental data. If select the fluctuation parameter values to have similar COV of IMEP, the range of the pp vs. ppl scatter is not wide enough. This is perhaps because of the limit of the combustion model to simulate precise pressure curves. Figure 4.14 (a) shows the MFB curves of simulation results whose peak pressure scatter matches with experimental data. Figure 4.14 (b) shows the MFB curves calculated from the experimental pressures. It can be seen that the difference between distributions of simulated MFB curves and experimental ones are not as large as the different between their COV of IMEP. This issue needs to be further studied in the future by improving the accuracy of the combustion model.

Table 4.4: COV of IMEP of simulation and experimental results

\begin{tabular}{|c|c|c|c|}
\hline TEST & Lambda & COV IMEP (sim) & COV IMEP (exp) \\
\hline 1640 & 1.0 & $3.6092 \%$ & $1.3429 \%$ \\
\hline 1642 & 1.1 & $5.9191 \%$ & $1.6200 \%$ \\
\hline 1645 & 1.25 & $9.2299 \%$ & $3.8090 \%$ \\
\hline 1647 & 1.35 & $16.3712 \%$ & $7.9659 \%$ \\
\hline
\end{tabular}




\subsection{COMBUSTION STABILITY ANALYSIS}

For the lean combustion conditions, the burning duration is enlarged because of the slow laminar burning speed. The heat release has more space to vary because of the longer combustion duration. Another major cause of combustion stability should be the variation during the early flame formation, in which the laminar speed is the major part of flame propagation. The simulation results show the probability of large amount of variation in the early combustion under lean conditions. Comparing the MFB curves in Figure 4.3 and Figure 4.5, it is found that is much larger in lean condition (lambda $=1.35$ ).

Figure 4.3 and Figure 4.5 show the variations in MFB curves of stoichiometric and lean (lambda $=1.35$ ) conditions. The stoichiometric MFB curves have better stability. Most of stoichiometric combustion have short burn duration and the phase located around MBT point with CA50 around 7 9 deg ATDC. On the other hand, the MFB curves in lean conditions are worse in stability. A lot of them have late phase and slow burning rate.

To study the effect of cyclic variation causes, the calibrated variance value of the flame development variation source in the lean condition (lambda $=1.35$ ) is included for the simulation in the stoichiometric condition. Figure 4.18 (a) shows the MFB results of the simulation and the experimental MFB curves are shown in Figure 4.18 (b). Similarly, the variance value of eddy burning time calibrated in stoichiometric condition is introduced in the simulation of lean combustion condition (lambda $=1.35$ ). Figure 4.19 (a) shows the simulation results and the experimental MFB curves of lean condition (lambda = 1.35) are shown in Figure 4.19 (b). From the results of the first simulation, it is found that even though with large variation in the early stage of combustion, stoichiometric condition provides relatively fast burning environment which restricts the growth of deviation. In the second simulation, even though under the severe lean combustion condition, the MFB curves concentrate while combustion proceeding and the very late and partial burn cycles are avoided. 


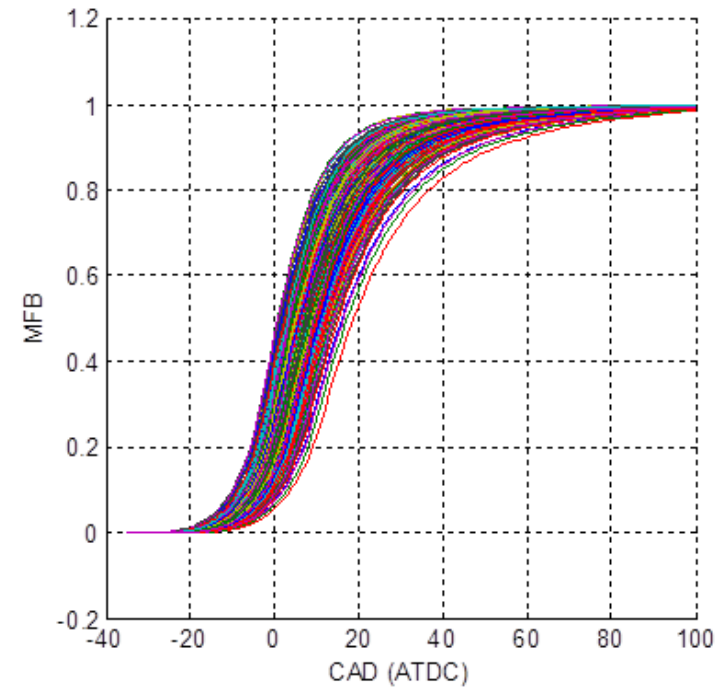

(a)



(b)

Figure 4.18: (a) MFB curves of simulation introduced with large variance in early flame burning (b) experimental data, test 1640,600 cycles, lambda $=1$.



(a)

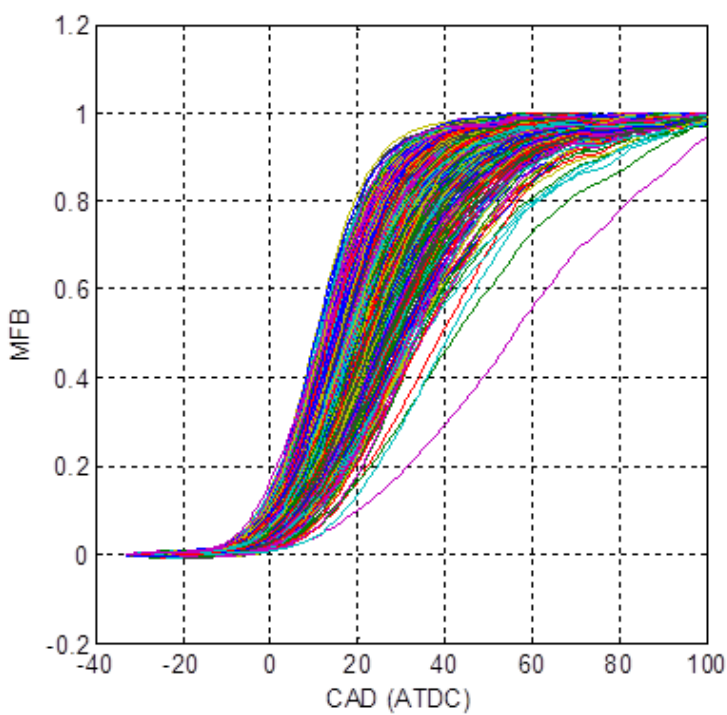

(b)

Figure 4.19: (a) MFB curves of simulation introduced with small variance in eddy burning time (b) experimental result, test 1647, 600 cycles, lambda $=1.35$. 
The combustion efficiency is also studied for stable combustion. Spark-ignition engines achieve the maximum efficiency when spark ignition is set at the MBT point. The MBT cycle has the pressure versus chamber volume curve most similar to that of ideal combustion model. The ideal combustion cycle of SI engine uses that all of the energy from fuel releases at the TDC point to raise in-cylinder pressure. The cycles that vary from the MBT cycle have lower efficiency [12].

An indicator of combustion efficiency or fuel economy is the specific fuel consumption $(s f c)$ expressed in equation (36). In the presented combustion model, $s f c$ of each cycle is calculated with the fuel mass estimated by intake pressure, temperature and the actual AFR etc.

$$
s f c=\frac{\dot{m}_{f}}{\text { Power }}
$$

By choosing the optimal spark ignition timing the combustion could be controlled in MBT phase. Most of the cycles could operate around MBT phase if the combustion is stable. For combustion with large variation, the phases of more cycles are deviated from the required MBT phase. Consequently the efficiency loss increases when the variation becomes large. Figure 4.20 to Figure 4.23 show the $s f c$ distributions from simulation results under different lean combustion conditions. The $s f \mathcal{c}$ values of most cycles locate on the left side of the distribution in stable combustion condition. Only small amount of cycles have large differences. However, in the lean combustion condition, the number of cycles with large $s f c$ values increases and also their deviations from the lowest $s f c$ cycle is increased. Comparing these figures the width of the distribution range increases as the increasing of lean combustion level. 


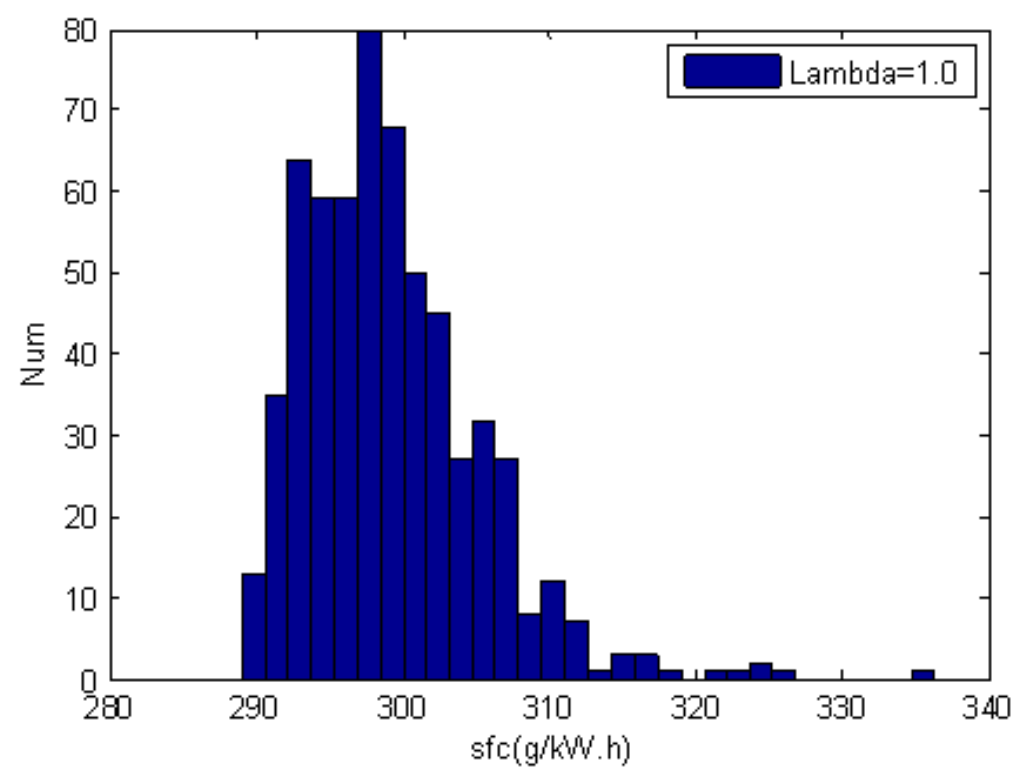

Figure 4.20: Distribution of $s f c$ calculated from simulation result, test 1640 , lambda $=1$.

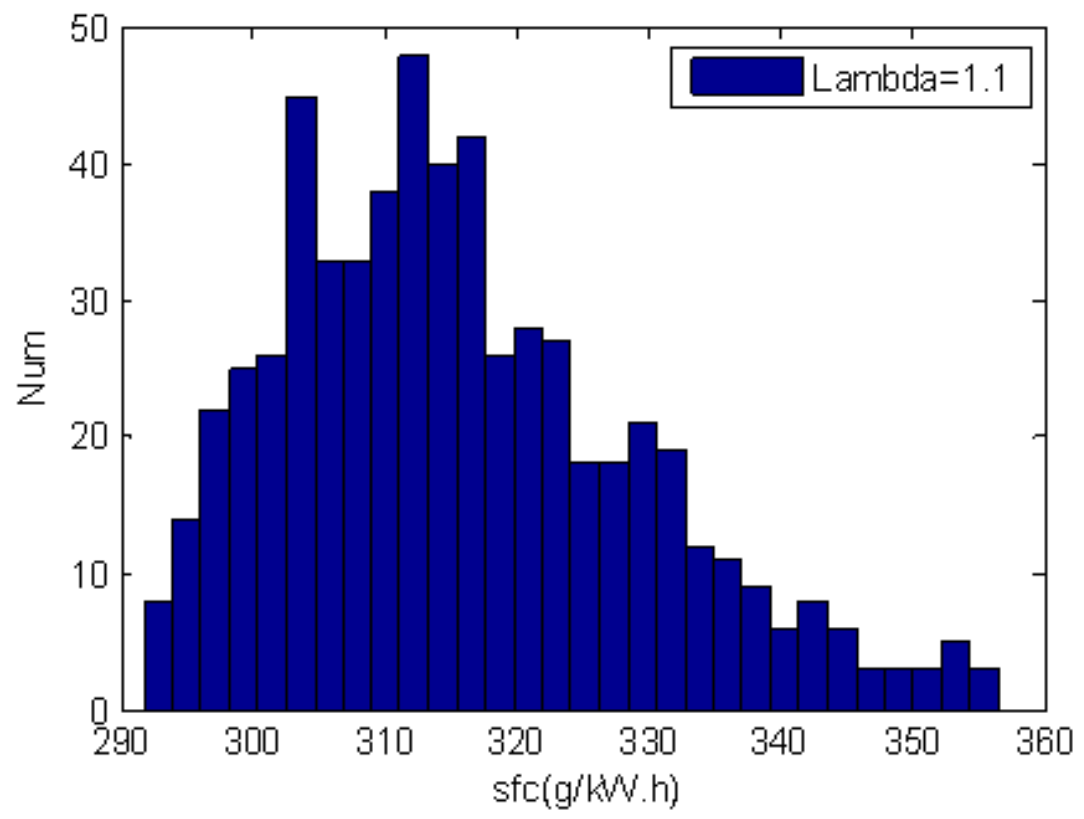

Figure 4.21: Distribution of $s f c$ calculated from simulation result, test 1642 , lambda $=1.1$. 


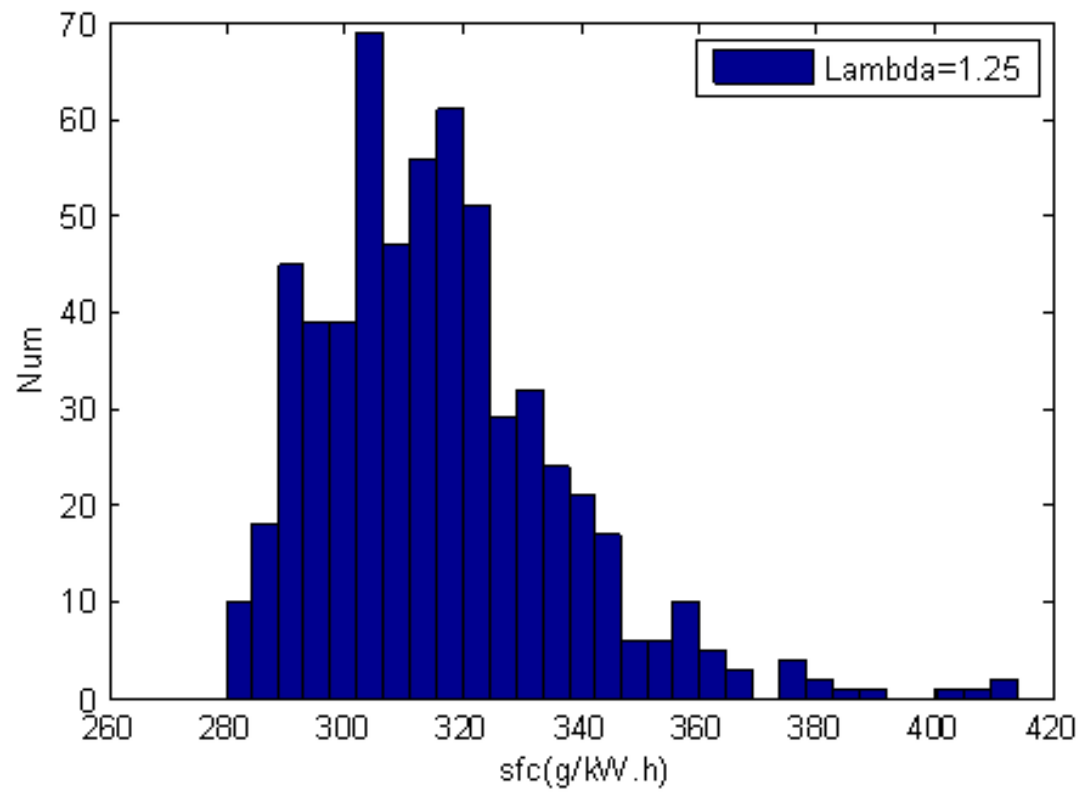

Figure 4.22: Distribution of $s f c$ calculated from simulation result, test 1645 , lambda $=$ 1.25 .

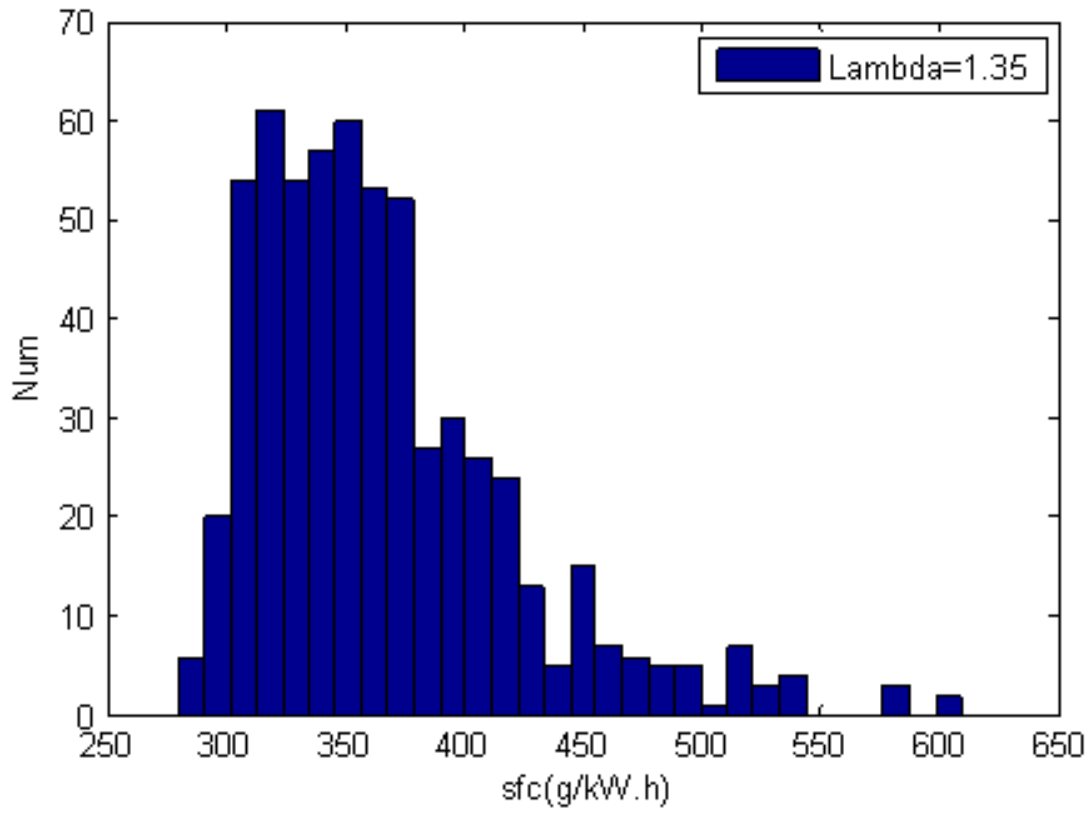

Figure 4.23: Distribution of $s f c$ calculated from simulation result, test 1647 , lambda $=$ 1.35 . 


\section{CONCLUSIONS AND FUTURE WORKS}

A zero-dimensional fundamental combustion model proposed by several authors is studied and implemented in Simulink to simulate in-cylinder pressure for a Ford Ecoboost 3.5L central ignited SI engine. The combustion process is described as turbulent flame propagation and large eddy burning with laminar flame speed. With assumption of spherical flame geometry and using two-zone thermodynamic model, the presented combustion model is able to predict mass density temperature and pressure variables. The simulation results of in-cylinder pressure and MFB are approximately matched with engine experimental data under various operation conditions.

The cyclic variation of consecutive combustion cycles exists in in-cylinder pressure traces. This variation increases when an engine operates in leaner combustion conditions. This phenomenon could be simulated by introducing variation sources of engine parameters, eddy burning time and the early flame development rate. The variance values are chosen to make peak pressure scatter match that of experimental result. The calibrated variation values of different lean level simulations reveals that the variations of eddy burning time and early flame development rate increase in lean combustion conditions. Cyclic variation caused by the early deviation and growth during the long combustion period leads efficiency losses due to the wide range of $s f c$ distribution.

For the future work, physical explanations of fuel economy increase before the lean limit can be explored with the combustion model. Further analysis needs more capable combustion model. The combustion model includes laminar flame speed in the flame propagation. Actually simulation result shows dominant turbulent propagation speed from very start of combustion. The effect of laminar flame speed in the early flame formation needs to be studied and evolved into the combustion model. In addition, the

presented model needs to be validated with experimental data of more operation conditions. More detail of engine conditions such as residual gas fraction and ignition process could be considered in the simulation. The presented combustion model also needs to be modified to simulate more precise mass burn rate and in-cylinder pressure in lean combustion conditions. The eddy burning rate during the last half of combustion 
needs to be refined to predict more precise mass burning rate values. The amounts of variation sources introduced in the multi-cycle simulation under different lean levels need to be quantified. Comparisons of other combustion matrices and under more operation conditions are needed. And also further study of the variation source and amounts introduced in the model is needed to simulate the asymmetry of $10 \sim 90 \%$ burn duration distribution under lean conditions. 


\section{REFERENCES}

1. Ayala, F.A. and J.B. Heywood, Lean SI Engines: The role of combustion variability in defining lean limits. 2007, Consiglio Nazionale delle Ricerche.

2. Rhodes, D.B. and J.C. Keck, Laminar Burning Speed Measurements of IndoleneAir-Diluent Mixtures at High Pressures and Temperatures. 1985, SAE International.

3. Keck, J.C., Turbulent flame structure and speed in spark-ignition engines. Symposium (International) on Combustion, 1982. 19(1): p. 1451-1466.

4. Wong, V.W. and D.P. Hoult, Rapid Distortion Theory Applied to Turbulent Combustion. 1979, SAE International.

5. Keck, J.C., J.B. Heywood, and G. Noske, Early Flame Development and Burning Rates in Spark Ignition Engines and Their Cyclic Variability. 1987, SAE International.

6. Blizard, N.C. and J.C. Keck, Experimental and Theoretical Investigation of Turbulent Burning Model for Internal Combustion Engines. 1974, SAE International.

7. Tabaczynski, R.J., C.R. Ferguson, and K. Radhakrishnan, A Turbulent Entrainment Model for Spark-Ignition Engine Combustion. 1977, SAE International.

8. Tabaczynski, R.J., F.H. Trinker, and B.A.S. Shannon, Further refinement and validation of a turbulent flame propagation model for spark-ignition engines. Combustion and Flame, 1980. 39(2): p. 111-121.

9. Ayala, F.A. and Massachusetts Institute of Technology. Department of Mechanical Engineering., Combustion lean limits fundamentals and their application to a SI hydrogen-enhanced engine concept. 2006. p. 205 p.

10. Guezennec, Y.G. and W. Hamama, Two-Zone Heat Release Analysis of Combustion Data and Calibration of Heat Transfer Correlation in an I. C. Engine. 1999, SAE International.

11. Ayala, F.A., M.D. Gerty, and J.B. Heywood, Effects of Combustion Phasing, Relative Air-fuel Ratio, Compression Ratio, and Load on SI Engine Efficiency. 2006, SAE International.

12. Heywood, J.B., Internal combustion engine fundamentals. 1988, New York: McGraw-Hill. xxix, 930 p.

13. Beretta, G.P., M. Rashidi, and J.C. Keck, Turbulent Flame Propagation and Combustion in Spark-Ignition Engines. Combustion and Flame, 1983. 52(3): p. 217-245.

14. Yeliana, et al., The Calculation of Mass Fraction Burn of Ethanol-Gasoline Blended Fuels Using Single and Two-Zone Models. 2008, SAE International.

15. Rashidi, M., The nature of cycle-by-cycle variation in the S.I. Engine from high speed photographs. Combustion and Flame, 1981. 42(0): p. 111-122.

16. Abdi Aghdam, E., et al., Study of Cyclic Variation in an SI Engine Using QuasiDimensional Combustion Model. 2007, SAE International.

17. Tennekes, H. and J.L. Lumley, A first course in turbulence. 1972, Cambridge, Mass.,: MIT Press. xii, 300 p. 
18. Woschni, G., A Universally Applicable Equation for the Instantaneous Heat Transfer Coefficient in the Internal Combustion Engine. 1967, SAE International.

19. Fox, J.W., W.K. Cheng, and J.B. Heywood, A Model for Predicting Residual Gas Fraction in Spark-Ignition Engines. 1993, SAE International.

20. Robert Bosch GmbH., Gasoline-engine management. 2nd ed. 2004, Bury St Edmunds: Professional Engineering. 418 p. 


\section{APPENDIX A}

\section{MATLAB SCRIPTURE OF COMBUSTION MODEL SETUP}

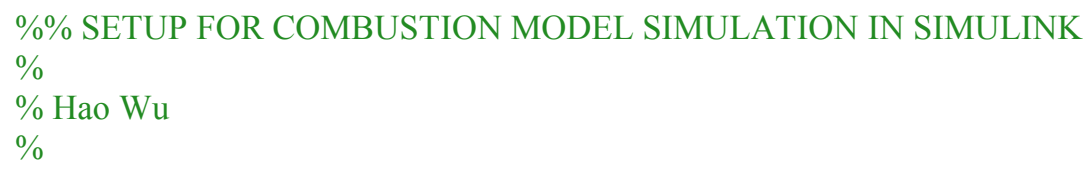




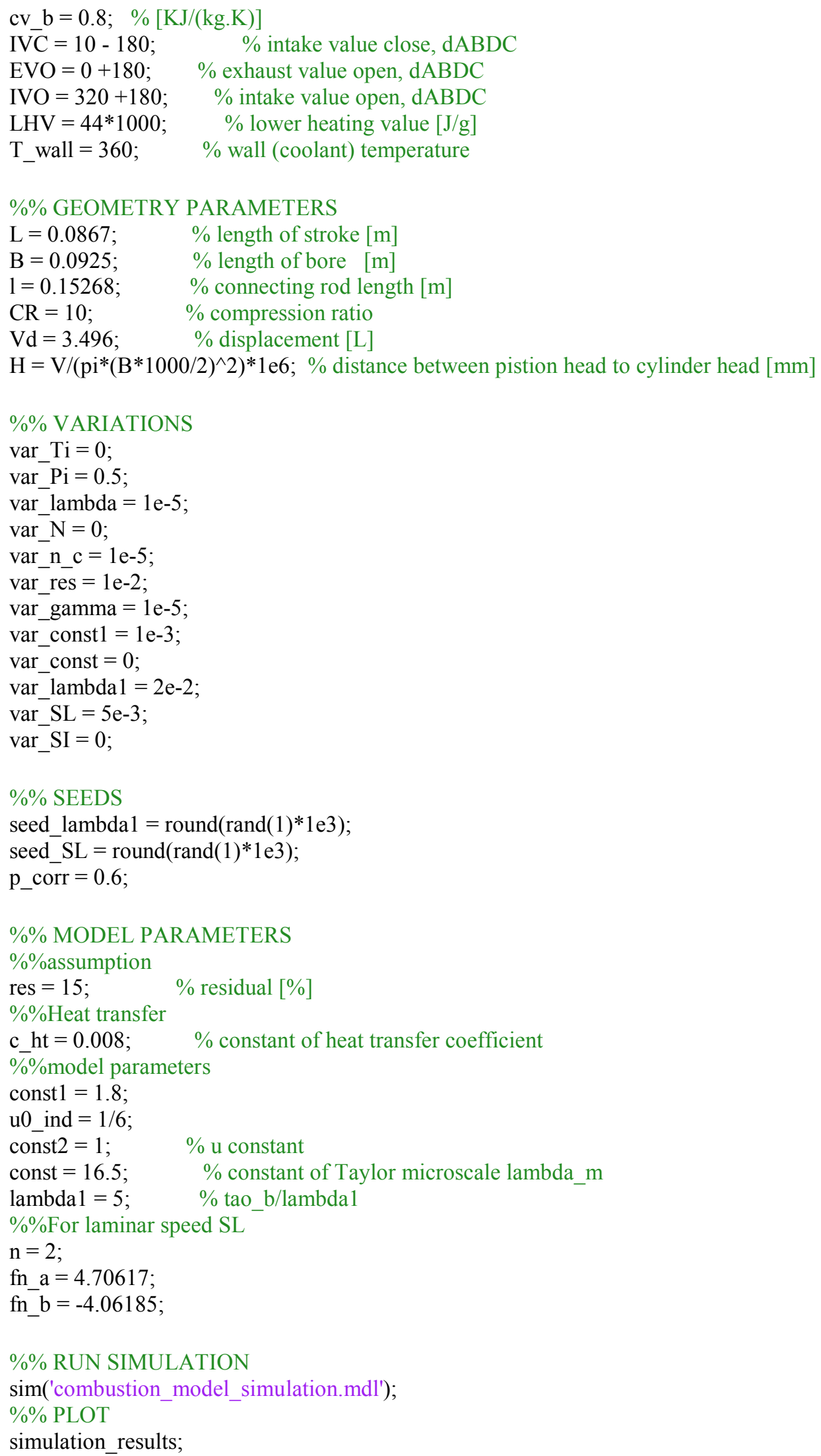




\section{APPENDIX B}

GRAPIC PROGRAM OF COMBUSTION MODEL IN SIMULINK ENVIRONMENT

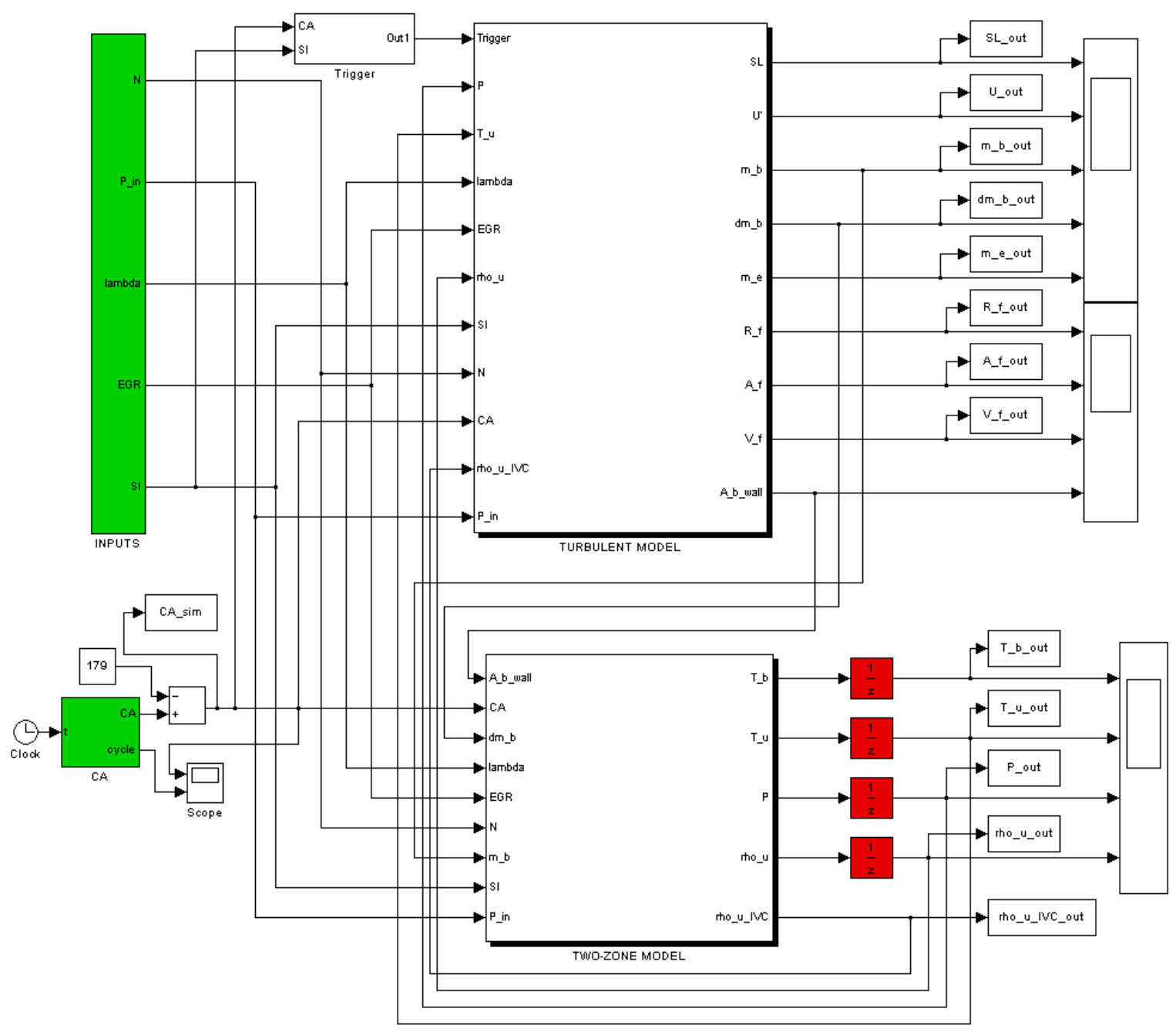

Appendix 1: First layer of fundamental combustion model in SIMULINK graphic design environment. 